\title{
Application of 3-nitrooxypropanol and canola oil to mitigate enteric methane emissions of beef cattle results in distinctly different effects on the rumen microbial community
}

Robert J Gruninger ( $\square$ robert.gruninger@canada.ca )

Agriculture and Agri-Food Canada https://orcid.org/0000-0001-8693-6990

Xiu Min Zhang

Chinese Academy of Sciences

Megan L. Smith

University of Delaware

Limin Kung

University of Delaware

Diwakar Vyas

University of Florida

Sean M. McGinn

Agriculture and Agri-Food Canada Lethbridge Research and Development Centre

Maik Kindermann

DSM Nutritional Products Inc

Min Wang

Chinese Academy of Sciences

Zhi Liang Tan

Chinese Academy of Sciences

Karen A. Beauchemin

Agriculture and Agri-Food Canada Lethbridge Research and Development Centre

\section{Research Article}

Keywords: 3-nitrooxypropanol, canola oil, enteric methane emissions, beef cattle, rumen microbial community

Posted Date: April 9th, 2021

DOl: https://doi.org/10.21203/rs.3.rs-391068/v1 
License: (c) (i) This work is licensed under a Creative Commons Attribution 4.0 International License. Read Full License 


\section{Abstract}

Background: The major GHG from ruminants is enteric methane $\left(\mathrm{CH}_{4}\right)$ which in 2010, was estimated at $2.1 \mathrm{Gt}$ of $\mathrm{CO}_{2}$ equivalent, accounting for $4.3 \%$ of global $\mathrm{GHG}$ emissions. There re extensive efforts being made around the world to develop methane mitigating inhibitors that specifically target rumen methanogens with the ultimate goal of reducing the environmental footprint of ruminant livestock production. This study examined the individual and combined effects of supplementing a high-forage diet (90\% barley silage) fed to beef cattle with the investigational methane $\left(\mathrm{CH}_{4}\right)$ inhibitor 3nitrooxypropanol (3-NOP) and canola oil (OIL) on the rumen microbial community in relation to enteric $\mathrm{CH}_{4}$ emissions and ruminal fermentation.

Results: 3-NOP and OIL individually reduced enteric $\mathrm{CH}_{4}$ emission (-28.2\% and $-24.0 \%$, respectively), and the effects were additive when used in combination (-51.3\%). 3-NOP increased $\mathrm{H}_{2}$ emissions 37 fold, while co-administering 3-NOP and OIL increased $\mathrm{H}_{2}$ in the rumen 20-fold relative to the control diet. The inclusion of 3-NOP or OIL reduced the diversity of the rumen microbiome. 3-NOP resulted in targeted changes in the microbiome decreasing the relative abundance of Methanobrevibacter and increasing the relative abundance of Bacteroidetes. The inclusion of OIL resulted in large scale changes to the microbial community that were associated with changes in ruminal volatile fatty acid concentration and gas production. OIL significantly reduced the abundance of protozoa and fiber-degrading microbes in the rumen but it did not selectively alter the abundance of rumen methanogens.

Conclusions: Our data provide a mechanistic understanding of $\mathrm{CH}_{4}$ inhibition by 3-NOP and OIL when fed alone and in combination to cattle. 3-NOP specifically targeted rumen methanogens inhibiting the hydrogenotrophic methanogenesis pathway and resulting in increased $\mathrm{H}_{2}$ emissions and propionate production. In contrast, OIL caused large scale changes in the rumen microbial community by indiscriminately altering the abundance of a range of rumen microbes, reducing the abundance of fibrolytic bacteria and altering rumen fermentation. Importantly, our data suggests that co-administering $\mathrm{CH}_{4}$ inhibitors with distinct mechanisms of action can both enhance $\mathrm{CH}_{4}$ inhibition and provide alternative sinks to prevent excessive accumulation of ruminal $\mathrm{H}_{2}$.

\section{Background}

Ruminant production systems need to embrace the challenge of reducing greenhouse gas emissions $(\mathrm{GHG})$ to be in sync with other sectors of society that are adopting net-zero emission goals. The major GHG from ruminants is enteric methane $\left(\mathrm{CH}_{4}\right)$, which in 2010 , was estimated at $2.1 \mathrm{Gt}$ of $\mathrm{CO}_{2}$ equivalent, accounting for $4.3 \%$ of global $\mathrm{GHG}$ emissions [1]. Enteric $\mathrm{CH}_{4}$ is a potent $\mathrm{GHG}$ with a 28-times greater global warming potential than carbon dioxide $\left(\mathrm{CO}_{2}\right)$ when compared on an equivalent basis $\left(\mathrm{CO}_{2} \mathrm{e}\right)$ over 100-years. Enteric $\mathrm{CH}_{4}$ emissions also represent a loss of $2-12 \%$ of the gross energy consumed by ruminants [2]. Developing effective mitigation strategies to reduce enteric $\mathrm{CH}_{4}$ from ruminants therefore 
has the potential to increase production efficiency and reduce the environmental impact of ruminant livestock.

Dietary supplements and feed additives have been extensively investigated for their potential to decrease enteric $\mathrm{CH}_{4}$ emissions from ruminants [3, 4]. Of the mitigation options available, synthesized inhibitors have been found to be highly effective in inhibiting methanogenesis in the rumen when supplemented to the diet as feed additives [4]. However, many of these compounds (e.g., bromochloromethane, chloroform) are highly toxic, cause undesirable side-effects, or decrease methanogenesis only transiently. One exception is 3-nitrooxypropanol (3-NOP; DSM Nutritional Products, Basel, Switzerland), an investigational compound that has been shown to consistently decrease enteric $\mathrm{CH}_{4}$ emissions by 20 to $80 \%$ with no signs of animal toxicity [5-8]. Hristov et al (2015) reported a 25 to $32 \%$ decrease in $\mathrm{CH}_{4}$ production in lactating dairy cows that persisted over a 12-week study when 3-NOP was included in the ration at 40 to $80 \mathrm{mg} / \mathrm{kg}$ dry matter (DM) [9]. A dose response study identified a quadratic decrease in enteric $\mathrm{CH}_{4}$ emissions in dairy cattle with maximum reduction of $\mathrm{CH}_{4}$ yield with 3-NOP included at 100 to $200 \mathrm{mg} / \mathrm{kg}$ DM [10]. In a study with growing beef cattle, a 37 to $42 \%$ decrease in enteric $\mathrm{CH}_{4}$ emissions occurred over 238-days when 3-NOP was supplemented at 125 to $200 \mathrm{mg} / \mathrm{kg}$ DM [11]. Similarly, MartinezFernandez et al. (2019) reported that $\mathrm{CH}_{4}$ emissions were decreased by $38 \%$ in steers fed 3-NOP (2.5 $\mathrm{g} /$ day). Furthermore, studies that have examined the impact of 3-NOP on fiber digestion in the rumen or total-tract have reported no negative effects $[6,12,13]$.

3-Nitrooxypropanol is a structural analogue of methyl coenzyme $\mathrm{M}$ and acts as a competitive inhibitor that selectively binds to methyl coenzyme M reductase (MCR)[14]. Binding of 3-NOP oxidizes the catalytic nickel ion from $\mathrm{Ni}^{+}$to $\mathrm{Ni}^{2+}$ temporarily inactivating the MCR enzyme and inhibiting the last step of methanogenesis [14]. In vitro assays with pure cultures of key rumen microbes revealed that 3-NOP very specifically inhibited the growth of rumen methanogens at low doses and had limited effect on the growth characteristics of the rumen bacteria tested [14]. There have been few studies that have examined the impact of 3-NOP on the composition of the rumen microbial community. Haisan et al. (2016) used qPCR to show that 3-NOP significantly decreased 16S rRNA gene copy numbers for methanogens, and tended to decrease the total number of bacteria in rumen contents of dairy cows [15]. Another study using next-generation sequencing found that 3-NOP decreased microbial alpha diversity in the rumen and resulted in a decrease in the relative abundance of hydrogenotrophic methanogens but had limited effects on rumen bacteria [16]. Most recently, it was shown that 3-NOP reduced the alpha diversity of the microbial community colonizing the surface of feed in the rumen of beef heifers and specifically reduced the abundance of methanogens without causing large changes to the overall composition of the microbial community [13]. Other studies have reported that 3-NOP supplementation did not change the abundance of methanogens or total bacteria in beef cattle [17] or sheep [6]. Further research is needed to understand the effects that 3-NOP has on the rumen microbial community in terms of composition and function. 
The addition of lipids to the diet of ruminants is another effective method of decreasing enteric $\mathrm{CH}_{4}$ emissions, and has the added benefit of enhancing digestible energy content of the feed [18]. The inclusion of lipids can also modify the fatty acid composition of milk and meat in a manner that enhances the health benefits associated with consuming these products [19]. The effectiveness with which lipid supplementation decreases enteric $\mathrm{CH}_{4}$ emissions varies and is dependent on diet composition, lipid composition (chain length and degree of saturation), inclusion level in the diet, and lipid source (oilseed vs. oil) [20]. In addition to reducing $\mathrm{CH}_{4}$ emissions, high fat diets are known to decrease fiber digestibility and may affect $\mathrm{DM}$ intake (DMI). Therefore, the maximum recommended total dietary lipid concentration is typically 60 to $80 \mathrm{~g} / \mathrm{kg}$ DM (30 to $50 \mathrm{~g} / \mathrm{kg}$ DM of added lipid) [20, 21]. Several meta-analyses of the literature found that $10 \mathrm{~g} / \mathrm{kg} \mathrm{DM}$ addition of lipid to the diet reduces $\mathrm{CH}_{4}$ yield (g/kg DMI) by up to $5.6 \%[20,22-24]$. The microbial basis with which dietary lipids decrease methanogenesis is not fully understood but is thought to be due to: 1) a decrease in the amount of organic matter fermented in the rumen; 2 ) a decrease in the abundance of rumen methanogens and protozoa; and 3) provision of alternative $\mathrm{H}_{2}$ sinks through biohydrogenation of unsaturated fatty acids [20]. Previous studies examining the impact of dietary lipids on the rumen microbial community did not observe a reduction in the abundance of rumen methanogens; however, the rumen microbial community was altered by specifically reducing the abundance of fibrolytic bacteria and protozoa $[21,25,26]$.

The present study examines the impact of 3-NOP and canola oil supplementation alone, and in combination, on the rumen microbial community. An in depth analysis of the impacts of these treatments on rumen metabolism and enteric gas emissions has been published in a complementary manuscript [27]. We examine how the observed alternations in the rumen microbiome are influenced by enteric gas emissions and rumen fermentation in beef cattle consuming a high forage diet. Rumen samples were collected over a $12 \mathrm{~h}$ period and the treatment effects were examined using a meta-taxonomic approach targeting the 16s rRNA gene. We hypothesized that 3-NOP has a highly targeted effect on rumen methanogens and that the inclusion of canola oil causes large, non-specific changes in the composition and function of the rumen microbial community. The aim of the study was to provide information that could be used to develop effective $\mathrm{CH}_{4}$ mitigation strategies.

\section{Results}

\section{Sequencing of rumen samples}

A total of 192 samples of rumen fluid and digesta were sequenced, resulting in 11,657,704 non-chimeric sequences after quality control and the identification of 6,217 unique ASVs from all samples. The minimum number of sequences per sample was 36,270 and the maximum was 95,904 . Rarefaction analysis show that sequencing depth was sufficient to capture most of the microbial diversity in the samples with rarefaction curves for all samples approaching an asymptote.

\section{Addition of 3-NOP and OIL reduced microbial diversity}


The effect of 3-NOP, OIL and 3-NOP + OIL as a function of time on the alpha diversity of the rumen samples is shown in Table 1. Supplementing diets with 3-NOP resulted in a numerical reduction in observed ASVs at $0 \mathrm{~h}(P=0.095)$, and a significant decrease in ASVs 6 and $12 \mathrm{~h}$ after feeding $(P \leq 0.05)$. 3-NOP decreased the phylogenetic diversity of rumen fluid at all of the sampling time points $(P \leq 0.05)$. The inclusion of OIL significantly decreased the number of ASVs and phylogenetic diversity of rumen fluid at all of the time points $(P \leq 0.001)$. No interactions between 3-NOP and OIL were found on the alpha diversity of rumen fluid. 3-NOP decreased alpha diversity of rumen digesta at $12 \mathrm{~h}(P \leq 0.05)$ but there was no significant effect at 0 and $6 \mathrm{~h}(P>0.05)$. The addition of OIL decreased the observed ASVs and phylogenetic diversity of rumen digest at all of the time points $(P<0.001)$. There was an interaction between 3-NOP and OIL on the phylogenetic diversity in rumen digesta at $0 \mathrm{~h}(P=0.024)$ but not at 6 and $12 \mathrm{~h}$. 
Table 1

The impact of feeding diets supplemented with (+) and without (-)3-NOP and OIL on the a-diversity of the rumen microbial community at 0,6 and $12 \mathrm{~h}$ after feeding in beef cattle ${ }^{1}$.

\begin{tabular}{|c|c|c|c|c|c|c|c|c|}
\hline \multirow[t]{2}{*}{ Item } & \multicolumn{2}{|c|}{$-3-N O P$} & \multicolumn{2}{|c|}{ + 3-NOP } & \multirow[t]{2}{*}{ SEM } & \multicolumn{3}{|c|}{$\begin{array}{l}P \\
\text { value }\end{array}$} \\
\hline & -OIL & +OIL & -OIL & +OIL & & $\begin{array}{l}\text { 3- } \\
\text { NOP }\end{array}$ & OIL & $\begin{array}{l}\text { 3-NOP x } \\
\text { OIL }\end{array}$ \\
\hline \multicolumn{9}{|l|}{ Rumen Fluid } \\
\hline \multicolumn{9}{|l|}{$\mathrm{Oh}$} \\
\hline Observed ASVs & 560 & 406 & 501 & 383 & 23.7 & 0.095 & $\begin{array}{l}< \\
0.001\end{array}$ & 0.46 \\
\hline $\begin{array}{l}\text { Phylogenetic } \\
\text { diversity }\end{array}$ & 45.5 & 34.9 & 41.5 & 33.4 & 0.72 & 0.014 & $\hat{0}_{0.001}$ & 0.25 \\
\hline \multicolumn{9}{|l|}{$6 \mathrm{~h}$} \\
\hline Observed ASVs & 536 & 379 & 457 & 335 & 28.8 & 0.021 & $\begin{array}{l}<.001 \\
0\end{array}$ & 0.49 \\
\hline $\begin{array}{l}\text { Phylogenetic } \\
\text { diversity }\end{array}$ & 43.8 & 33.7 & 38.2 & 30.8 & 1.23 & 0.001 & $<.001$ & 0.24 \\
\hline \multicolumn{9}{|l|}{$12 \mathrm{~h}$} \\
\hline Observed ASVs & 528 & 393 & 429 & 344 & 32.1 & 0.002 & $\begin{array}{l}<.001 \\
0\end{array}$ & 0.27 \\
\hline $\begin{array}{l}\text { Phylogenetic } \\
\text { diversity }\end{array}$ & 43.0 & 34.1 & 37.7 & 31.4 & 1.28 & 0.013 & 0.001 & 0.37 \\
\hline \multicolumn{9}{|l|}{ Rumen Digesta } \\
\hline \multicolumn{9}{|l|}{$\mathrm{Oh}$} \\
\hline Observed ASVs & 820 & 614 & 738 & 657 & 32.3 & 0.55 & $\begin{array}{l}<.001 \\
0\end{array}$ & 0.062 \\
\hline $\begin{array}{l}\text { Phylogenetic } \\
\text { diversity }\end{array}$ & $54.8^{\mathrm{a}}$ & $42.6^{c}$ & $50.3^{b}$ & $43.6^{c}$ & 1.47 & 0.14 & $\begin{array}{l}< \\
0.001\end{array}$ & 0.024 \\
\hline \multicolumn{9}{|l|}{$6 \mathrm{~h}$} \\
\hline Observed ASVs & 747 & 592 & 696 & 603 & 17.7 & 0.46 & $<.001$ & 0.26 \\
\hline $\begin{array}{l}\text { Phylogenetic } \\
\text { diversity }\end{array}$ & 50.3 & 42.4 & 48.2 & 42.1 & 1.69 & 0.37 & $\hat{0}_{0.001}$ & 0.49 \\
\hline
\end{tabular}

${ }^{1}$ OIL = canola oil; 3-NOP = 3-nitrooxypropanol.

a,b,c Values within a row with different letters differ $(P \leq 0.05)$ 


\begin{tabular}{|c|c|c|c|c|c|c|c|c|}
\hline \multirow[t]{2}{*}{ Item } & \multicolumn{2}{|c|}{$-3-N O P$} & \multicolumn{2}{|c|}{ + 3-NOP } & \multirow[t]{2}{*}{ SEM } & \multicolumn{3}{|c|}{$\begin{array}{l}P \\
\text { value }\end{array}$} \\
\hline & - OIL & +OIL & -OIL & + OIL & & $\begin{array}{l}\text { 3- } \\
\text { NOP }\end{array}$ & OIL & $\begin{array}{l}\text { 3-NOP x } \\
\text { OIL }\end{array}$ \\
\hline \multicolumn{9}{|l|}{$12 \mathrm{~h}$} \\
\hline Observed ASVs & 810 & 604 & 686 & 582 & 7.1 & 0.017 & $\begin{array}{l}< \\
0.001\end{array}$ & 0.084 \\
\hline $\begin{array}{l}\text { Phylogenetic } \\
\text { diversity }\end{array}$ & 52.5 & 42.1 & 47.5 & 40.3 & 2.44 & 0.006 & $<.001$ & 0.14 \\
\hline \multicolumn{9}{|c|}{${ }^{1} \mathrm{OIL}=$ canola oil; 3-NOP = 3-nitrooxypropanol. } \\
\hline
\end{tabular}

\section{Effect of 3-NOP and OIL supplementation on overall microbiome composition}

Rumen fluid and rumen digesta samples clustered separately in PCoA plots based on both weighted and unweighted UniFrac calculations ( $P<0.001 ;$ Fig. 1$)$. Samples also clustered separately based on treatment in PcoA plots based on both weighted and unweighted UniFrac distances. For all plots, the control samples clustered distinctly from 3-NOP, OIL, or 3-NOP + OIL $(P<0.001)$ samples. The inclusion of OIL alone had the largest effect on the composition of the microbial community and with samples containing OIL significantly separated from control and 3-NOP samples $(P<0.001)$. Sampling time did not have a significant effect on the clustering of samples $(P \geq 0.26)$; however, a PERMANOVA analysis revealed that samples collected prior to morning feeding were different from 6 and $12 \mathrm{~h}$ samples $(P=$ 0.006). There was no significant difference between 6 and $12 \mathrm{~h}$ samples $(P=0.56)$.

\section{Effect of 3-NOP and OIL on rumen methanogens}

The total number of ASVs that were assigned to the phylum Euryarchaeota in rumen digesta samples was significantly higher than in rumen fluid samples (Fig. 2). Methanobrevibacter was the most abundant methanogen in both rumen solids and digesta. Sampling time did not significantly affect methanogen abundance in either rumen fluid or digesta ( $P \geq 0.30$ ); however, 3-NOP alone and in combination with OIL had a significant effect on methanogen abundance in both rumen fluid and digesta $(P<0.001)$. 3-NOP $(P$ $<0.01)$ and 3-NOP + OIL $(P<0.001)$ significantly reduced the total number of Euryarchaeota ASVs in rumen fluid and rumen digesta samples (Fig. <link rid="fig2">2</link>A and 2, respectively). The effects of 3-NOP and OIL on microbial abundance were generally independent of one another but there was a significant interaction between 3-NOP and OIL on the relative abundance of Euryarchaeota $(P<0.05$, Tables 2 and 3). 3-NOP and 3-NOP + OIL caused significant decreases in the abundance of Methanobrevibacter $(P<0.05)$, Methanomicrobium $(P<0.001)$, Methanomethylophilus $(P<0.001)$, and an uncultured genus of Thermoplasmatales $(P<0.001)$. The addition of OIL decreased the abundance of Euryarchaeota in rumen fluid $(P<0.01)$. In contrast, the addition of OIL resulted in a significant increase in 
the abundance of Euryarchaeota in rumen digesta $(P<0.05)$. The effects observed for OIL treatment resulted in broad spectrum changes in the methanogen community and could not be attributed to a change in the abundance of a specific methanogen genus. 
Table 2

Impact of feeding diets supplemented with (+) and without (-) 3-NOP and OIL on the relative abundance of phyla identified in rumen fluid in beef cattle ${ }^{1}$

\begin{tabular}{|c|c|c|c|c|c|c|c|c|}
\hline \multirow[t]{2}{*}{ Item } & \multicolumn{2}{|c|}{$-3-N O P$} & \multicolumn{2}{|c|}{ + 3-NOP } & \multirow[t]{2}{*}{ SEM } & \multicolumn{3}{|c|}{$P$-value } \\
\hline & - OIL & +OIL & - OIL & +OIL & & $\begin{array}{l}3- \\
\text { NOP }\end{array}$ & OIL & 3-NOP $\times$ OIL \\
\hline \multicolumn{9}{|l|}{$\mathrm{Oh}$} \\
\hline Euryarchaeota & 1.18 & 0.71 & 0.62 & 0.21 & 0.165 & $<.001$ & 0.002 & 0.80 \\
\hline Bacteroidetes & $54.9^{\mathrm{b}}$ & $59.7^{\mathrm{ab}}$ & $57.4^{\mathrm{ab}}$ & $62.7^{a}$ & 2.75 & 0.11 & 0.007 & 0.023 \\
\hline Firmicutes & 19.3 & 21.8 & 18.6 & 21.2 & 3.03 & 0.60 & 0.052 & 0.93 \\
\hline Fibrobacteres & 10.6 & 0.26 & 10.2 & 0.14 & 1.16 & 0.81 & $<.001$ & 0.89 \\
\hline Actinobacteria & 0.40 & 0.15 & 0.54 & 0.14 & 0.158 & 0.67 & 0.038 & 0.62 \\
\hline Proteobacteria & 4.18 & 12.0 & 3.48 & 12.0 & 1.55 & 0.81 & $<.001$ & 0.84 \\
\hline Spirochaetae & 1.97 & 2.36 & 3.48 & 1.89 & 0.532 & 0.31 & 0.24 & 0.061 \\
\hline Verrucomicrobia & 4.10 & 1.24 & 3.65 & 0.82 & 0.586 & 0.30 & $\begin{array}{l}< \\
0.001\end{array}$ & 0.97 \\
\hline Others $(<0.5 \%)$ & 3.31 & 1.79 & 2.09 & 0.94 & 0.341 & $\begin{array}{l}< \\
0.001\end{array}$ & $<.001$ & 0.43 \\
\hline$F: B$ & 0.32 & 0.34 & 0.29 & 0.31 & 0.009 & 0.17 & 0.43 & 0.95 \\
\hline \multicolumn{9}{|l|}{$6 \mathrm{~h}$} \\
\hline Euryarchaeota & $0.89^{a}$ & $0.54^{\mathrm{b}}$ & $0.17^{c}$ & $0.11^{\mathrm{c}}$ & 0.072 & $\begin{array}{l}< \\
0.001\end{array}$ & 0.002 & 0.016 \\
\hline Bacteroidetes & 45.0 & 49.5 & 53.1 & 49.9 & 2.77 & 0.042 & 0.75 & 0.059 \\
\hline Firmicutes & 25.5 & 24.6 & 18.3 & 25.1 & 2.92 & 0.21 & 0.27 & 0.15 \\
\hline Fibrobacteres & 7.68 & 0.06 & 6.04 & 0.02 & 1.018 & 0.39 & $<.001$ & 0.42 \\
\hline Actinobacteria & 2.15 & 0.22 & 0.98 & 0.39 & 0.553 & 0.34 & 0.022 & 0.20 \\
\hline
\end{tabular}

${ }^{1} \mathrm{OIL}=$ canola oil; 3-NOP = 3-nitrooxypropanol.

a,b,c Values within a row with different letters differ $(P \leq 0.05)$

$\mathrm{F}: \mathrm{B}=$ Firmicutes: Bacteroidetes 


\begin{tabular}{|c|c|c|c|c|c|c|c|c|}
\hline \multirow[t]{2}{*}{ Item } & \multicolumn{2}{|c|}{$-3-N O P$} & \multicolumn{2}{|c|}{ + 3-NOP } & \multirow[t]{2}{*}{ SEM } & \multicolumn{3}{|c|}{$P$-value } \\
\hline & - OIL & +OIL & -OIL & +OIL & & $\begin{array}{l}3- \\
\text { NOP }\end{array}$ & OIL & 3-NOP $\times$ OIL \\
\hline Proteobacteria & 12.5 & 22.1 & 15.2 & 23.1 & 3.79 & 0.58 & 0.016 & 0.79 \\
\hline Spirochaetae & 2.36 & 1.25 & 3.66 & 0.81 & 0.538 & 0.43 & 0.001 & 0.12 \\
\hline Verrucomicrobia & 2.22 & 0.66 & 1.64 & 0.27 & 0.237 & 0.019 & $\begin{array}{l}<.001 \\
0\end{array}$ & 0.64 \\
\hline Others $(<0.5 \%)$ & 1.72 & 1.02 & 0.89 & 0.34 & 0.192 & $<.001$ & $<.001$ & 0.54 \\
\hline F: B & 0.50 & 0.44 & 0.28 & 0.43 & 0.040 & 0.076 & 0.28 & 0.086 \\
\hline \multicolumn{9}{|l|}{$12 \mathrm{~h}$} \\
\hline Euryarchaeota & 0.85 & 0.63 & 0.26 & 0.12 & 0.086 & $<.001$ & 0.003 & 0.47 \\
\hline Bacteroidetes & 50.8 & 49.3 & 52.0 & 55.6 & 2.24 & 0.070 & 0.60 & 0.20 \\
\hline Firmicutes & 17.3 & 20.4 & 13.6 & 19.5 & 2.20 & 0.21 & 0.023 & 0.46 \\
\hline Fibrobacteres & 11.7 & 0.16 & 11.3 & 0.06 & 1.37 & 0.87 & $\begin{array}{l}< \\
0.001\end{array}$ & 0.93 \\
\hline Actinobacteria & 0.86 & 0.28 & 0.63 & 0.32 & 0.252 & 0.66 & 0.053 & 0.55 \\
\hline Proteobacteria & 11.2 & 25.8 & 15.4 & 22.3 & 3.06 & 0.92 & 0.002 & 0.21 \\
\hline Spirochaetae & 2.40 & 1.31 & 3.75 & 1.19 & 0.564 & 0.21 & 0.001 & 0.14 \\
\hline Verrucomicrobia & 2.61 & 0.83 & 1.96 & 0.44 & 0.286 & 0.041 & $\dot{0}_{0.001}$ & 0.59 \\
\hline Others $(<0.5 \%)$ & 2.26 & 1.19 & 1.08 & 0.50 & 0.188 & $\begin{array}{l}< \\
0.001\end{array}$ & $\begin{array}{l}< \\
0.001\end{array}$ & 0.21 \\
\hline F: B & 0.32 & 0.38 & 0.23 & 0.31 & 0.026 & 0.037 & 0.042 & 0.39 \\
\hline \multicolumn{9}{|c|}{${ }^{1}$ OIL = canola oil; 3-NOP = 3-nitrooxypropanol. } \\
\hline \multicolumn{9}{|c|}{ a,b,c Values within a row with different letters differ $(P \leq 0.05)$} \\
\hline $\mathrm{F}: \mathrm{B}=$ Firmicutes: & Bactero & etes & & & & & & \\
\hline
\end{tabular}


Table 3

Impact of feeding diets supplemented with (+) and without (-) 3-NOP and OIL on the relative abundance of phyla identified in rumen digesta in beef cattle at 0,6 and $12 \mathrm{~h}$ after feeding ${ }^{1}$

\begin{tabular}{|c|c|c|c|c|c|c|c|c|}
\hline \multirow[t]{2}{*}{ Item } & \multicolumn{2}{|c|}{-3-NOP } & \multicolumn{2}{|c|}{ + 3-NOP } & \multirow[t]{2}{*}{ SEM } & \multicolumn{3}{|c|}{$\begin{array}{l}P \\
\text { value }\end{array}$} \\
\hline & -OIL & + OIL & -OIL & + OIL & & 3-NOP & OIL & $\begin{array}{l}\text { 3-NOP x } \\
\text { OIL }\end{array}$ \\
\hline \multicolumn{9}{|l|}{$O \mathrm{~h}^{1}$} \\
\hline Euryarchaeota & $3.43^{b}$ & $6.04^{\mathrm{a}}$ & $2.18^{b}$ & $1.69^{b}$ & 0.631 & $<.001$ & 0.031 & 0.003 \\
\hline Bacteroidetes & 24.4 & 36.9 & 30.0 & 39.0 & 1.56 & 0.005 & $\begin{array}{l}< \\
0.001\end{array}$ & 0.15 \\
\hline Firmicutes & 48.4 & 51.3 & 45.0 & 52.7 & 1.55 & 0.49 & 0.001 & 0.096 \\
\hline Fibrobacteres & 14.6 & 0.06 & 11.8 & 0.05 & 1.45 & 0.33 & $<$ & 0.34 \\
\hline Actinobacteria & 1.22 & 0.74 & 1.58 & 1.17 & 0.368 & 0.25 & 0.19 & 0.91 \\
\hline Proteobacteria & 1.15 & 2.28 & 0.90 & 2.53 & 0.293 & 0.98 & $\begin{array}{l}< \\
0.001\end{array}$ & 0.40 \\
\hline Spirochaetae & 4.43 & 1.54 & 6.73 & 1.81 & 0.707 & 0.078 & $<$ & 0.16 \\
\hline Verrucomicrobia & 0.72 & 0.29 & 0.67 & 0.30 & 0.080 & 0.71 & $\begin{array}{l}< \\
0.001\end{array}$ & 0.67 \\
\hline $\mathrm{F}: \mathrm{B}$ & 1.92 & 1.37 & 1.47 & 1.33 & 0.118 & 0.026 & 0.002 & 0.063 \\
\hline Others $(<0.5 \%)$ & 1.59 & 0.85 & 1.14 & 0.74 & 0.171 & 0.11 & 0.002 & 0.32 \\
\hline \multicolumn{9}{|l|}{$6 \mathrm{~h}$} \\
\hline Euryarchaeota & $3.24^{\mathrm{a}}$ & $4.11^{\mathrm{a}}$ & $1.39^{b}$ & $0.96^{\mathrm{b}}$ & 0.466 & $\begin{array}{l}<.001 \\
0.00\end{array}$ & 0.44 & 0.030 \\
\hline Bacteroidetes & 23.8 & 33.2 & 30.5 & 35.5 & 1.34 & 0.001 & $<$ & 0.056 \\
\hline Firmicutes & $52.1^{\mathrm{a}}$ & $51.6^{\mathrm{ab}}$ & $46.6^{b}$ & $51.9^{a}$ & 1.43 & 0.052 & 0.068 & 0.032 \\
\hline Fibrobacteres & 9.97 & 0.05 & 9.27 & 0.03 & 1.18 & 0.75 & $<$ & 0.77 \\
\hline
\end{tabular}

${ }^{1} \mathrm{OIL}=$ canola oil; 3-NOP = 3-nitrooxypropanol.

a,b,c Values within a row with different letters differ $(P \leq 0.05)$

$\mathrm{F}: \mathrm{B}=$ Firmicutes: Bacteroidetes 


\begin{tabular}{|c|c|c|c|c|c|c|c|c|}
\hline \multirow[t]{2}{*}{ Item } & \multicolumn{2}{|c|}{$-3-N O P$} & \multicolumn{2}{|c|}{ + 3-NOP } & \multirow[t]{2}{*}{ SEM } & \multicolumn{3}{|c|}{$\begin{array}{l}P \\
\text { value }\end{array}$} \\
\hline & -OIL & +OIL & -OIL & +OIL & & 3-NOP & OIL & $\begin{array}{l}\text { 3-NOP x } \\
\text { OlL }\end{array}$ \\
\hline Actinobacteria & 4.00 & 0.83 & 2.62 & 1.49 & 1.17 & 0.74 & 0.061 & 0.36 \\
\hline Proteobacteria & 2.69 & 8.23 & 3.95 & 8.31 & 1.122 & 0.52 & $<.001$ & 0.58 \\
\hline Spirochaetae & 2.47 & 1.11 & 4.46 & 1.14 & 0.525 & 0.065 & $<.001$ & 0.073 \\
\hline Verrucomicrobia & 0.53 & 0.23 & 0.51 & 0.19 & 0.067 & 0.62 & $\begin{array}{l}<.001 \\
0.00\end{array}$ & 0.90 \\
\hline F: B & $2.17^{b}$ & $1.54^{\mathrm{a}}$ & $1.52^{\mathrm{a}}$ & $1.45^{\mathrm{a}}$ & 0.145 & 0.002 & 0.004 & 0.020 \\
\hline Others $(<0.5 \%)$ & 1.18 & 0.60 & 0.73 & 0.50 & 0.170 & 0.10 & 0.023 & 0.29 \\
\hline \multicolumn{9}{|l|}{$12 \mathrm{~h}$} \\
\hline Euryarchaeota & $3.11^{b}$ & $4.51^{\mathrm{a}}$ & $1.48^{\mathrm{C}}$ & $0.84^{\mathrm{C}}$ & 0.498 & $\begin{array}{l}< \\
0.001\end{array}$ & 0.25 & 0.005 \\
\hline Bacteroidetes & 26.7 & 35.9 & 32.7 & 39.2 & 1.20 & $<.001$ & $<.001$ & 0.22 \\
\hline Firmicutes & 50.0 & 49.2 & 44.9 & 50.1 & 1.52 & 0.14 & 0.13 & 0.044 \\
\hline Fibrobacteres & 9.38 & 0.09 & 8.18 & 0.06 & 1.052 & 0.55 & $<.001$ & 0.57 \\
\hline Actinobacteria & 2.73 & 0.69 & 2.17 & 1.28 & 0.848 & 0.98 & 0.052 & 0.43 \\
\hline Proteobacteria & 2.90 & 7.51 & 4.06 & 6.71 & 0.959 & 0.85 & 0.001 & 0.31 \\
\hline Spirochaetae & $2.96^{\mathrm{b}}$ & $1.14^{\mathrm{C}}$ & $5.18^{a}$ & $1.19^{c}$ & 0.531 & 0.041 & $\begin{array}{l}< \\
0.001\end{array}$ & 0.051 \\
\hline Verrucomicrobia & 0.56 & 0.28 & 0.51 & 0.20 & 0.069 & 0.27 & $\begin{array}{l}<.001 \\
0 .\end{array}$ & 0.76 \\
\hline F: B & 1.85 & 1.35 & 1.35 & 1.27 & 0.115 & 0.005 & 0.004 & 0.064 \\
\hline Others $(<0.5 \%)$ & 1.69 & 0.69 & 0.90 & 0.46 & 0.342 & 0.14 & 0.046 & 0.42 \\
\hline \multicolumn{9}{|c|}{${ }^{1} \mathrm{OIL}=$ canola oil; 3-NOP = 3-nitrooxypropanol. } \\
\hline \multicolumn{9}{|c|}{$\mathrm{a}, \mathrm{b}, \mathrm{c}$ Values within a row with different letters differ $(P \leq 0.05)$} \\
\hline $\mathrm{F}: \mathrm{B}=$ Firmicutes: & acteroic & tes & & & & & & \\
\hline
\end{tabular}


The addition of 3-NOP, OIL and 3-NOP + OIL resulted in significant changes to the composition of the rumen bacterial community. The relative abundance of bacterial taxa in rumen fluid and digesta samples as a function of treatment and time are shown in Tables 2 and 3, respectively. The most abundant phyla in all samples were Bacteroidetes and Firmicutes regardless of time and treatment. Together these two phyla made up between $68-92 \%$ of the sequences identified. There was no effect of 3-NOP addition on the abundance of Bacteroidetes in rumen fluid samples before feeding $(P=0.11)$ but there was a significant increase after $6 \mathrm{~h}$ after feeding $(P=0.042)$ and a tendency for greater abundance in samples $12 \mathrm{~h}$ after feeding $(P=0.070)$. The addition of 3-NOP significantly increased the abundance of Bacteroidetes in rumen digesta at all of the time points $(P \leq 0.05)$. This effect was primarily due to an increase in the relative abundance of Prevotella_1 (Supplementary Tables 1 and 2). The addition of OIL to the diet also resulted in an increase in the abundance of Bacteriodetes in the rumen fluid before morning feeding $(P=0.007)$, but not $6 \mathrm{~h}(P=0.75)$ or $12 \mathrm{~h}$ later $(P=0.60)$. The effect of OIL on rumen digesta samples was similar, with a significant increase in the abundance of Bacteroidetes at all of the time points due to an increase in the relative abundance of Prevotella_1 $(P<0.001)$. Conversely, there were decreases in the abundance of other genera including RC9 gut group $(P \leq 0.01)$, S24-7 $(P \leq 0.02)$, and RF16 ( $0 \mathrm{~h}$ and $6 \mathrm{~h} P \leq 0.002$ ). A significant interaction between treatments was observed in rumen fluid prior to feeding but not at other time points. There was no significant interaction between OIL and 3-NOP in rumen digesta.

The addition of 3-NOP did not significantly change the relative abundance of Firmicutes in rumen fluid at any of the time points (Table 2). However, at the genus level, 3-NOP supplementation significantly altered the abundance of several uncharacterized genera within this phylum (Supplementary Table 1 ). In contrast, the abundance of Firmicutes in rumen digesta was reduced at $6 \mathrm{~h}$ after feeding $(P=0.052)$ but not in the $0 \mathrm{~h}$ samples $(P=0.49)$ or $12 \mathrm{~h}$ after feeding $(P=0.13)$ (Table 3$)$. OlL increased the abundance of Firmicutes before feeding $(P=0.052)$ and $12 \mathrm{~h}$ after feeding $(P=0.023)$ but not $6 \mathrm{~h}$ after feeding $(P=$ 0.27 ) in rumen fluid samples (Table 2). There was a significant increase in the abundance of Firmicutes in the rumen digesta as a result of OIL addition before feeding $(P=0.001)$ and a tendency to be higher at $6 \mathrm{~h}$ after feeding $(P=0.068)$, but no significant difference at $12 \mathrm{~h}$ after feeding $(P=0.14)$ (Table 3$)$. At the genus level, there were significant decreases in the abundance in Christensenellaceae R-7 group at all of the time points in rumen digesta but not in rumen fluid (Supplementary Tables 1 and 2). OIL supplementation resulted in an increase in the relative abundance of Ruminococcus_1 $(P \leq 0.001)$ and Succinoclasticum $(P \leq 0.001)$ (Supplementary Tables 1 and 2$)$. The majority of other genera within Firmicutes that showed significant change in abundance due to the addition of OIL were unknown and/or uncultured taxa. There was a significant interaction between treatments on the relative abundance of Firmicutes in rumen digesta $6 \mathrm{~h}(P=0.032)$ and $12 \mathrm{~h}(P=0.044)$ after feed was consumed. All treatments resulted in a significant decrease in the Firmicutes:Bacteroidetes ratio in rumen digesta samples primarily due to the increase in the abundance of Prevotella_1 (Supplementary Tables 1 and 2).

The relative abundance of Proteobacteria in both rumen fluid and digesta was not affected by the addition of 3-NOP (Tables 2 and 3). In contrast, OIL supplementation resulted in a significant increase in Proteobacteria in both rumen fluid and digesta at all of the time points $(P<0.001)$. The impact of OIL on 
Proteobacteria was primarily due to increases in the abundance of Ruminobacter and an uncultured group of Succinivibrionaceae (Supplementary Tables 1 and 2). The addition of 3-NOP did not affect the abundance of Fibrobacteres, Spirochaetae, or Verrucomicrobia in any of the samples but the addition of OIL reduced the abundance of all three of these phyla. The most dramatic effect of OIL was observed for the genus Fibrobacter. The addition of OIL to the diet resulted in a large decrease in the number sequences attributable to Fibrobacter $(41-243$ fold decrease; $P<0.001)$ in both rumen fluid and digesta at all of the time points (Tables 2 and 3). There was also an interaction between OIL and 3-NOP that resulted in a larger decrease in the abundance of Fibrobacter $(75-382$ fold decrease; $P<0.001)$ in animals receiving 3-NOP + OIL. The relative abundance of Spirochatae in the rumen digesta was reduced at all of the time points in animals receiving OIL. Similarly, OIL decreased the abundance of Spirochatae in rumen fluid 6 and $12 \mathrm{~h}$ after feeding but not in samples taken prior to morning feeding. All of these sequences were attributed to the genus Treponema_2 (Supplementary Tables 1 and 2). The abundance of Verrucomicrobia was lowered by the addition of OIL relative to control at all of the time points in both rumen fluid and rumen digesta.

\section{Addition of Oil altered protozoal community in rumen fluid}

The impact that the addition of OIL and 3-NOP had on the composition of rumen protozoa was assessed by microscopic analysis of rumen fluid samples (Table 4). The addition of 3-NOP did not alter the total number of protozoa or the composition of the protozoal community at any time point. In contrast, the addition of OIL resulted in a significant decrease of up to 16 -fold $(P<0.001)$ in the total number of protozoa at all of the time points. OIL altered the composition of the protozoal community significantly decreasing the abundance of Dasytricha spp., Entodinium spp., Ostracodinium spp., and Osphyoscolex spp. in all samples and Metadinium spp. at $0 \mathrm{~h}$ and $12 \mathrm{~h}$. No interaction effects between 3-NOP and OIL were observed for protozoa. 
Table 4

Impact of feeding diets supplemented with (+) and without (-) 3-NOP and OIL on the protozoal populations (cell $/ \mathrm{mL}$ ) in the rumen fluid of beef at 0,6 and $12 \mathrm{~h}$ after feeding ${ }^{1}$.

\begin{tabular}{|c|c|c|c|c|c|c|c|c|}
\hline \multirow[t]{2}{*}{ Item } & \multicolumn{2}{|c|}{$-3-N O P$} & \multicolumn{2}{|c|}{ +3-NOP } & \multirow[t]{2}{*}{ SEM } & \multicolumn{3}{|c|}{$P$-value } \\
\hline & - OIL & +OIL & - OIL & +OIL & & $\begin{array}{l}3- \\
\text { NOP }\end{array}$ & OIL & $\begin{array}{l}\text { 3-NOP x } \\
\text { OIL }\end{array}$ \\
\hline \multicolumn{9}{|l|}{$\mathrm{Oh}$} \\
\hline Isotricha spp. $\left(\times 10^{2}\right)$ & 1.25 & ND & 8.75 & ND & 4.69 & 0.40 & 0.26 & 0.40 \\
\hline Dasytricha spp. $\left(\times 10^{2}\right)$ & 11.3 & ND & 25.0 & ND & 14.1 & 0.42 & 0.037 & 0.42 \\
\hline \multicolumn{9}{|l|}{ Entodiniomorphs } \\
\hline Entodinium spp. $\left(\times 10^{5}\right)$ & 4.56 & 0.29 & 4.93 & 0.67 & 0.77 & 0.32 & $<.01$ & 0.97 \\
\hline $\begin{array}{l}\text { Ostracodinium spp. } \\
\left(\times 10^{2}\right)\end{array}$ & 10.0 & ND & 18.8 & ND & 9.88 & 0.47 & 0.020 & 0.47 \\
\hline Metadinium spp. $\left(\times 10^{2}\right)$ & 17.5 & ND & 16.3 & 1.25 & 10.2 & 0.99 & 0.002 & 0.80 \\
\hline $\begin{array}{l}\text { Osphyoscolex spp. } \\
\left(\times 10^{2}\right)\end{array}$ & 10.0 & ND & 17.5 & ND & 10.2 & 0.52 & 0.022 & 0.52 \\
\hline Total, $10^{5} \mathrm{cell} / \mathrm{mL}$ & 4.61 & 0.29 & 5.01 & 0.67 & 0.75 & 0.30 & $\begin{array}{l}<.01 \\
0.01\end{array}$ & 0.98 \\
\hline \multicolumn{9}{|l|}{$6 \mathrm{~h}$} \\
\hline Isotricha spp. $\left(\times 10^{2}\right)$ & 2.50 & ND & 3.75 & ND & 2.69 & 0.78 & 0.16 & 0.78 \\
\hline Dasytricha spp. $\left(\times 10^{2}\right)$ & 10.0 & ND & 8.75 & ND & 7.18 & 0.87 & 0.021 & 0.87 \\
\hline \multicolumn{9}{|l|}{ Entodiniomorphs } \\
\hline Entodinium spp. $\left(\times 10^{5}\right)$ & 3.89 & 0.25 & 4.41 & 0.58 & 0.74 & 0.27 & $<.01$ & 0.81 \\
\hline $\begin{array}{l}\text { Ostracodinium spp. } \\
\left(\times 10^{2}\right)\end{array}$ & 3.75 & ND & 8.75 & ND & 4.11 & 0.36 & 0.024 & 0.36 \\
\hline Metadinium spp. $\left(\times 10^{2}\right)$ & 1.25 & ND & 2.50 & ND & 1.63 & 0.65 & 0.17 & 0.65 \\
\hline $\begin{array}{l}\text { Osphyoscolex spp. } \\
\left(\times 10^{2}\right)\end{array}$ & 11.3 & ND & 12.5 & ND & 8.60 & 0.92 & 0.046 & 0.92 \\
\hline Total, $10^{5}$ cell $/ \mathrm{mL}$ & 3.92 & 0.25 & 4.45 & 0.58 & 0.73 & 0.26 & $\begin{array}{l}< \\
0.01\end{array}$ & 0.80 \\
\hline
\end{tabular}

${ }^{1} \mathrm{OIL}=$ canola oil, 3-NOP = 3-nitrooxypropanol. ND = Not detected 


\begin{tabular}{|c|c|c|c|c|c|c|c|c|}
\hline \multirow[t]{2}{*}{ Item } & \multicolumn{2}{|c|}{-3-NOP } & \multicolumn{2}{|c|}{ + 3-NOP } & \multirow[t]{2}{*}{ SEM } & \multicolumn{3}{|c|}{$P$-value } \\
\hline & - OIL & +OIL & - OIL & +OIL & & $\begin{array}{l}3- \\
\text { NOP }\end{array}$ & OIL & $\begin{array}{l}\text { 3-NOP x } \\
\text { OIL }\end{array}$ \\
\hline \multicolumn{9}{|l|}{$12 \mathrm{~h}$} \\
\hline Isotricha spp. $\left(\times 10^{2}\right)$ & ND & ND & 2.50 & ND & 1.25 & 0.32 & 0.32 & 0.32 \\
\hline Dasytricha spp. $\left(\times 10^{2}\right)$ & 5.00 & ND & 6.25 & ND & 4.53 & 0.84 & 0.07 & 0.84 \\
\hline \multicolumn{9}{|l|}{ Entodiniomorphs } \\
\hline Entodinium spp. $\left(\times 10^{5}\right)$ & 3.47 & 0.28 & 3.90 & 0.59 & 0.61 & 0.18 & $\begin{array}{l}<.01 \\
0.01\end{array}$ & 0.84 \\
\hline $\begin{array}{l}\text { Ostracodinium spp. } \\
\left(\times 10^{2}\right)\end{array}$ & 8.75 & ND & 5.00 & ND & 4.59 & 0.54 & 0.026 & 0.54 \\
\hline Metadinium spp. $\left(\times 10^{2}\right)$ & 3.75 & ND & 5.00 & ND & 2.79 & 0.76 & 0.033 & 0.76 \\
\hline $\begin{array}{l}\text { Osphyoscolex spp. } \\
\left(\times 10^{2}\right)\end{array}$ & 5.00 & ND & 11.3 & ND & 6.28 & 0.39 & 0.027 & 0.39 \\
\hline Total, $10^{5} \mathrm{cell} / \mathrm{mL}$ & 3.50 & 0.28 & 3.93 & 0.59 & 0.60 & 0.17 & $\begin{array}{l}<.01 \\
0.01\end{array}$ & 0.83 \\
\hline
\end{tabular}

\section{$\mathrm{CH}_{4}$ and $\mathrm{H}_{2}$ emissions}

A detailed analysis of the treatment effects on daily gaseous emissions is presented by Zhang et al., 2021 [27]. The present study examined the impact of 3-NOP and OIL on $\mathrm{CH}_{4}$ and $\mathrm{H}_{2}$ emissions, and concentration of $\mathrm{dH}_{2}$ over the day. A typical diurnal pattern of $\mathrm{CH}_{4}$ emissions was observed for control cattle, with a rapid increase in $\mathrm{CH}_{4}$ emissions peaking at $11.7 \mathrm{~g} / \mathrm{h} 3 \mathrm{~h}$ after feeding followed by a slow decrease to pre-feeding baseline levels of approximately $5 \mathrm{~g} / \mathrm{h}$ (Fig. 3A). Compared to control diets, supplementation with 3-NOP or OIL decreased the rate of $\mathrm{CH}_{4}$ emission by $28.2 \%$ and $23.9 \%$, respectively. There was a $51.4 \%$ decrease for the combined treatment which indicates that the effects of these mitigation strategies were additive (Fig. 3A). Feeding OIL or 3-NOP alone delayed the peak $\mathrm{CH}_{4}$ emission rate from $3 \mathrm{~h}$ in the control to $6 \mathrm{~h}$ after feeding, while emission rate for 3-NOP + OIL peaked $12 \mathrm{~h}$ after feeding. The greatest reduction in $\mathrm{CH}_{4}$ occurred in the first $6 \mathrm{~h}$ after feed consumption (Fig. 3A).

Enteric $\mathrm{H}_{2}$ emissions were minimal in cattle consuming the control or OIL supplemented diets (Fig. 3B). However, in cattle consuming 3-NOP supplemented diets, enteric $\mathrm{H}_{2}$ emissions rapidly increased 37-fold relative to control diets, peaking at $0.17 \mathrm{~g} / \mathrm{h}, 3 \mathrm{~h}$ after feeding. Co-administering 3-NOP and OIL increased

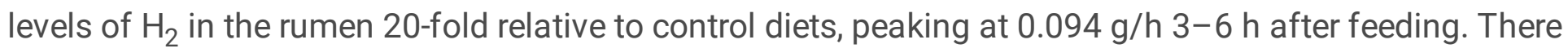


was also an increase in $\mathrm{dH}_{2}$ concentration in rumen fluid $(P<0.05)$. The inclusion of 3-NOP resulted in a significant increase in the peak concentration of $\mathrm{dH}_{2}$ in rumen fluid (Fig. 3C). The peak concentration of $\mathrm{dH}_{2}$ was observed $3 \mathrm{~h}$ after feeding and reached a concentration of $20.1 \mu \mathrm{mol} / \mathrm{L}$ in control diet. Inclusion of 3-NOP resulted in a 9.7-fold increase in the concentration of $\mathrm{dH}_{2}$ to $195.6 \mu \mathrm{mol} / \mathrm{L}$ compared to control $(P<0.05)$. The addition of both 3-NOP and OIL also resulted in an increase in $\mathrm{dH}_{2}$ concentration of 7.5fold relative to $151.0 \mu \mathrm{mol} / \mathrm{L}$ compared to control $(P<0.05)$.

\section{Changes in rumen fermentation and gas production were associated with the shifts in composition of the rumen microbiome}

Both $\mathrm{CH}_{4}$ mitigation strategies influenced a number of rumen fermentation parameters, gas production and dissolved $\mathrm{H}_{2}$ concentration. The influence of the treatments on animal metabolism is described in a separate manuscript [27]. Many of the observed changes in the rumen fermentation and gas production were significantly associated with the observed shifts in the rumen microbiome (Fig. 4). Samples from animals fed 3-NOP did not cluster separately in an NMDS ordination based on Bray-Curtis dissimilarity but $\mathrm{pH}\left(R^{2}=0.67 ; P=0.002\right)$ and $\mathrm{g} \mathrm{CH}_{4} / \mathrm{kg} \mathrm{DMI}\left(R^{2}=0.38 ; P=0.06\right)$ were significantly associated with the microbiome composition in rumen digesta. Rumen $\mathrm{pH}\left(R^{2}=0.45 ; P=0.034\right)$, acetate to propionate ratio $\left(R^{2}=0.45 ; P=0.04\right), \mathrm{g} \mathrm{H}_{2} / \mathrm{kg}$ of DMI $\left(R^{2}=0.38 ; P=0.06\right)$ and $\mathrm{g} \mathrm{CH}_{4} / \mathrm{kg} \mathrm{DMI}\left(R^{2}=0.84 ; P<0.0001\right)$ were significantly associated with the microbiome composition of rumen fluid. The inclusion of OIL resulted in large changes in the microbial community of rumen fluid and digesta and these shifts were significantly associated with total VFA concentration $\left(R^{2} \geq 0.48 ; P<0.05\right)$, the molar proportion of acetate $\left(R^{2} \geq 0.47\right.$; $P<0.05)$, isobutyrate $\left(R^{2} \geq 0.53 ; P<0.05\right)$, and butyrate $\left(R^{2} \geq 0.55 ; P<0.01\right)$, total protozoa $\left(R^{2} \geq 0.45 ; P\right.$ $<0.01)$, and $\mathrm{g} \mathrm{CH}_{4} / \mathrm{kg} \mathrm{DMI}\left(R^{2} 0.61 ; P<0.01\right)$. In addition to these factors, $\mathrm{pH}\left(R^{2} \geq 0.55 ; P \leq 0.01\right)$ and valerate proportion $\left(R^{2} \geq 0.44 ; P \leq 0.05\right)$ were associated with the observed changes in the microbial composition of rumen digesta due to OIL. The combination of NOP and OIL also resulted in distinct clustering of samples. Acetate $\left(R^{2} \geq 0.57 ; P<0.01\right)$, isobutyrate $\left(R^{2} \geq 0.42 ; P \leq 0.05\right)$, total VFA $\left(R^{2} \geq 0.44\right.$; $P \leq 0.05), \mathrm{NH}_{3}\left(R^{2} \geq 0.45 ; P<0.05\right), \mathrm{pH}\left(R^{2} \geq 0.47 ; P<0.05\right)$, protozoa count $\left(R^{2} \geq 0.59 ; P<0.01\right), \mathrm{g}$ $\mathrm{CH}_{4} / \mathrm{kg} \mathrm{DMI}\left(R^{2} 0.87 ; P<0.001\right)$, and $\mathrm{g} \mathrm{H}_{2} / \mathrm{kg} \mathrm{DMI}\left(R^{2} 0.45 ; P<0.05\right)$ were significantly associated with the changes in microbiome composition observed for the combined treatment.

\section{Discussion}

We studied the impact of supplementing a high forage diet with the investigational $\mathrm{CH}_{4}$ inhibitor 3-NOP and high levels of lipid (canola oil; OIL), alone and in combination, on the composition of the rumen microbial community and the relationship of these changes to rumen fermentation and enteric gaseous emissions. In a companion study, we found that diets that included 3-NOP had 31.6\% less $\mathrm{CH}_{4}$ yield $(\mathrm{g} / \mathrm{kg}$ $\mathrm{DMI}$ ) overall compared with those that did not contain 3-NOP, while addition of OIL decreased $\mathrm{CH}_{4}$ yield by $27.4 \%$ [27]. The $31.6 \%$ decrease in $\mathrm{CH}_{4}$ emissions ( $\mathrm{g} / \mathrm{kg}$ DMI) with 3-NOP supplementation $(200 \mathrm{mg} / \mathrm{kg}$ diet DM) that we observed is consistent with previous work that has reported a $30 \%-40 \%$ decrease in 
$\mathrm{CH}_{4}$ yield in cattle fed 3-NOP [7, 9-11, 28]. Similarly, the $27.4 \%$ decrease in $\mathrm{CH}_{4}$ yield for OIL was similar to expectations based on previous studies [20]. Importantly, co-administering 3-NOP and OIL treatments resulted in an incremental mitigation response. Treatments containing OIL resulted in large scale changes to the rumen microbial community associated with both rumen fluid and rumen digesta and these changes were persistent over the course of the day. PCoA clustering of samples based on both weighted and unweighted UniFrac distances indicate that the inclusion of OIL not only altered the abundance of rumen microbes but also changed the microbes that were present. In comparison, 3-NOP samples clustered much closer to control in weighted UniFrac but distinctly in unweighted UniFrac indicating that the primary impact of 3-NOP was limited to specific organisms.

\section{3-NOP reduced methanogenesis by reducing the abundance of hydrogenotrophic methanogens and} shifted fermentation towards alternative $\mathrm{H}_{2}$ sinks: 3-NOP decreased the bacterial alpha diversity as reflected by the decreased observed ASVs and phylogenetic diversity in rumen fluid samples but did not result in large scale shifts in the composition of the rumen microbial community. The relative abundance of ASVs in Bacteroidetes was increased in 3-NOP and 3-NOP + OIL treatments resulting in a decrease in the Firmicutes:Bacteroidetes ratio. Rumen Bacteroidetes are net $\mathrm{H}_{2}$ utilizers [29], and the increased $\mathrm{H}_{2}$ levels associated with 3-NOP containing diets may have provided a niche for the proliferation of Bacteroidetes.

Our results provide strong support that the decrease in enteric $\mathrm{CH}_{4}$ that is observed in animals consuming 3-NOP results from the targeted elimination of rumen methanogens. This is consistent with previous studies on 3-NOP's mechanism of action using pure cultures of rumen microbes. This in vitro work found that 3-NOP was highly specific for rumen methanogens even at low doses and had a minimal impact on rumen bacteria [14]. 3-NOP is a structural analogue of methyl coenzyme $\mathrm{M}$ and acts as a competitive inhibitor that selectively binds to MCR and temporarily inactivates the enzyme by oxidizing the catalytic nickel ion from $\mathrm{Ni}^{+}$to $\mathrm{Ni}^{2+}$. The significant reduction in the relative abundance of Euryarchaeota observed in this study supports the previous results and shows that in vivo, 3-NOP also has high specificity for methanogens.

3-NOP supplementation resulted in changes in rumen VFA concentration without large scale changes to the rumen microbial community. We hypothesize that the observed alterations in rumen fermentation are a result of alternative $\mathrm{H}_{2}$ sinks acting as terminal electron acceptors to capture some of the increased $\mathrm{H}_{2}$ observed in animals fed 3-NOP. There are a number of $\mathrm{H}_{2}$ sinks in the rumen the most important of which is the conversion of $\mathrm{CO}_{2}$ to $\mathrm{CH}_{4}$. Methane formation is the main $\mathrm{H}_{2}$ sink in the rumen and a consequence of inhibiting methanogenesis by 3-NOP supplementation is an accumulation of dissolved $\mathrm{H}_{2}$ and gaseous $\mathrm{H}_{2}$ emissions. In the absence of methanogenesis, the formation of the VFAs propionate, butyrate, and valerate can act as alternative $\mathrm{H}_{2}$ sinks [30]. Propionate is another principal alternative $\mathrm{H}_{2}$ sink in the rumen [31], and it appears that the accumulation of gaseous $\mathrm{H}_{2}$ and dissolved $\mathrm{H}_{2}$ in the rumen that resulted due to inhibiting methanogenesis shifted rumen metabolism in such a way that promoted propionate proportion. It has also been suggested that when dissolved $\mathrm{H}_{2}$ concentration is elevated in the 
rumen, fermentation pathways that are net generators of $\mathrm{H}_{2}$ such as acetate production are unfavorable [32]. The observed increase in dissolved $\mathrm{H}_{2}$ concentration, accompanied by decreased acetate and increased propionate percentages with 3-NOP (alone and in combination with OIL) supplementation observed in this study, are consistent with this observation [27]. The increased production of propionate does not incorporate all of the excess $\mathrm{H}_{2}$ when methanogenesis is inhibited and this can lead to an increase in gaseous $\mathrm{H}_{2}$ emissions as we observed in the present study [12]. The increase in propionate molar percentage and decrease in acetate molar percentage that we observed with 3-NOP (alone and in combination with oil) is consistent with previous studies [6, 27, 33].

\section{Oil supplementation caused large scale changes in the composition of the rumen microbiome and altered rumen fermentation}

OIL (alone and in combination with 3-NOP) had a large impact on the rumen microbial community and rumen fermentation. We observed reductions in the relative abundance of methanogens, large scale changes in the composition of the rumen bacterial population, elimination of rumen protozoa and keystone fibrolytic bacteria, and changes in VFA concentration and proportions. The inclusion of OIL shifted rumen fermentation pathways and resulted in increased propionate and decreased acetate proportions. OIL supplementation ( $\geq 4.0 \%$ of $\mathrm{DMI}$ ) has previously been reported to increase propionate and decrease acetate percentages for beef and dairy cattle [23,34].

Although we did not directly measure ruminal fiber digestion we observed significant decreases in a number of important fiber degrading rumen microbes including Fibrobacter, Bacteroidales BS11, and Bacteroidales RF16 when OIL was included in the diet. Fibrobacterwas decreased at all of the time points in both rumen fluid and rumen digesta by up to 382 -fold. Eliminating this keystone member of the rumen microbial community would undoubtedly reduce the efficiency of cellulose degradation. An in vitro study examining the $\mathrm{CH}_{4}$ inhibition potential of Tucumã oil observed a $25 \%$ reduction in DM disappearance in the rumen, significantly reduced microbial richness, with a 16-fold reduction in the abundance of Fibrobacter but no specific effect on methanogens [25]. Interestingly, we also observed a significant increase in the abundance of Ruminococcus_ 1 in OIL samples. Ruminococcus_ 1 is known to contain the keystone fiber degrading bacteria Ruminococcus flavifaciens and Ruminococcus albus [35]. We speculate that the elimination of Fibrobacterfrom the rumen of these animals may have provided an opportunity for other fiber degrading bacteria that are less sensitive to fatty acids to occupy the niche previously filled by Fibrobacter. Several Bacteroidetes were also significantly less abundant and are also well known to play important roles in carbohydrate metabolism. Bacteroidales BS11 gut group utilize hemicellulose monomeric sugars (e.g., xylose, fucose, mannose and rhamnose) and are involved in converting these to VFA [36]. Bacteroidales RF16 group are abundant in a range of ruminants when high forage diets are consumed suggesting a role in plant cell wall degradation [37-39]. The shift in VFA profile and the changes to the microbiome composition that accompanied the oil supplementation is consistent with a reduction in ruminal fiber degradation and suggests that fiber digestion was impaired in the animals consuming the OIL treatment [40]. This supposition is supported by the observed $18.0 \%$ and 
$23.3 \%$ decrease in total-tract digestibility of neutral detergent fiber when OIL was added to diets without and with 3-NOP, respectively [27].

A reduction in fiber digestion can favor a shift towards increased starch utilization in the rumen. We observed a significant increase in the abundance of the genera Succinivibrio and Ruminobacter within the phylum Proteobacteria in the OIL treatments both of which are known to play a role in starch metabolism $[41,42]$. Succinivibriaceae are known to metabolize starch and generate succinate which is an intermediate in the propionate pathway. Succiniclasticum was also significantly more abundant in OIL diets and can convert succinate into propionate [43]. This metabolic shift in the rumen would also contribute to the increased proportions of propionate and the low $\mathrm{H}_{2}$ emissions we observed in this treatment. Interestingly, several studies have found that Succinivibrionaceae is associated with reduced $\mathrm{CH}_{4}$ emissions, increased feed efficiency and higher propionate concentration [44, 45].

3-NOP and OIL have distinct mechanisms for reducing $\mathrm{CH}_{4}$ emissions: Combining mitigation strategies has the potential to further reduce enteric $\mathrm{CH}_{4}$ emissions from ruminant livestock and increase animal efficiency by increasing metabolizable energy availability. To date there has been little research conducted to identify effective combinations of inhibitors that have distinct modes of action and act synergistically or independently to reduce enteric $\mathrm{CH}_{4}$ production [4]. In the present study we observed very few interactions between 3-NOP and OIL, which is consistent with the unique mechanisms with which these compounds reduce enteric $\mathrm{CH}_{4}$ emissions. Notable exceptions where significant interactions were observed are: 1) acetate and propionate production, and 2) methanogen abundance. Compared to 3NOP treatment alone, co-administering 3-NOP and OIL resulted in an increase in propionate proportion with a concomitant decrease in acetate proportion as well as alterations in the lipid composition of the rumen fluid [27]. This can be interpreted as excess $\mathrm{H}_{2}$ being consumed through increased propionate production and biohydrogenation as intended. This is also consistent with the low $\mathrm{H}_{2}$ emissions that were observed when 3-NOP and OIL were fed together. The effect of 3-NOP and OIL on decreasing methanogen abundance is a significant result and shows that combinations of $\mathrm{CH}_{4}$ inhibitors can result in substantial reductions in methanogens. One explanation for the interaction between these inhibitors is that the impact of lipid on the protozoal community effectively reduced the abundance of methanogens associated with rumen protozoa and 3-NOP reduced the abundance of free-living methanogens. Although the inclusion of both 3-NOP and OIL had incremental effects on enteric $\mathrm{CH}_{4}$ emissions, the high lipid content of these diets impacted the abundance of fiber degrading bacteria in the rumen and this may have had a negative effect on feed digestibility in these animals. The reduction in fiber degradation resulting from the inclusion of high concentrations of lipids may outweigh the $\mathrm{CH}_{4}$ mitigating effects these lipids have in high performing animals. Additional research is needed to identify optimal inclusion levels that will maximize $\mathrm{CH}_{4}$ mitigation without sacrificing animal performance.

\section{Conclusions}


This study examined the impact of 3-NOP and canola oil supplementation as potential interventions to reduce enteric $\mathrm{CH}_{4}$ emissions associated with beef production. Our study found that these compounds are both effective treatments for reducing $\mathrm{CH}_{4}$ emissions; however, they have unique impacts on the rumen microbial community. 3-NOP is a highly targeted inhibitor that specifically reduces the activity of the dominant rumen methanogens and has minimal effects on other rumen microbes. In contrast, canola oil resulted in large scale shifts to the bacterial community and eliminated the majority of rumen protozoa. This caused a dramatic decrease in abundance of key fiber degrading rumen microbes, in particular Fibrobacter. Importantly, co-administering $\mathrm{CH}_{4}$ inhibitors with distinct mechanisms of action can both enhance $\mathrm{CH}_{4}$ inhibition and provide alternative $\mathrm{H}_{2}$ sinks to prevent excessive accumulation of ruminal $\mathrm{H}_{2}$.

\section{Methods}

The experiment was conducted at Agriculture and Agri-Food Canada's Research and Development Centre in Lethbridge, $A B$, Canada. Animals were cared for in accordance with the guidelines of the Canadian Council on Animal Care (2009). Full details of the animal metabolism trial are given in Zhang et al. 2021 [27].

Experimental Design and Dietary Treatments: Eight ruminally cannulated beef heifers (Angus cross, 732 $\pm 43 \mathrm{~kg}$ ) were used in a double $4 \times 4$ Latin square design with four 28-d periods and 4 dietary treatments arranged as a 2 (3-NOP, with and without) $\times 2$ (oil, with and without) factorial. All animals were adapted to their respective diets from day $1-13$ of each period and the remaining 15 days were used for measurements and sample collection. The dietary treatments were: 1) control (basal diet, CON); 2) 3-NOP alone (200 mg/kg of diet DM; 3-NOP, DSM Nutritional Products Ltd., Kaiseraugst, Switzerland); 3) canola oil alone (50g/kg DM, OIL; Loveland Industries, Inc., Loveland, CO, USA); and 4) 3-NOP (200 mg/kg of diet DM) and canola oil (50 g/kg DM) combined (3-NOP + OIL). Animals were blocked according to body weight and then randomly assigned to one of the 4 treatments. The animals were fed a high forage diet that consisted of (DM basis) $900 \mathrm{~g} / \mathrm{kg}$ barley silage, $41.2 \mathrm{~g} / \mathrm{kg}$ dry rolled barley grain, $50 \mathrm{~g} / \mathrm{kg}$ supplement mix and $8.8 \mathrm{~g} / \mathrm{kg}$ treatment mix (control or treatment). Both treatment mixes were prepared weekly and refrigerated, before being fully mixed with the diet. Total mixed rations (TMR) were mixed daily and animals were fed at 10:00 h.

Rumen Sampling: Rumen content samples were obtained on day 14 of each period at 3 time points: prior to feeding $(0 \mathrm{~h}), 6 \mathrm{~h}$ and $12 \mathrm{~h}$ after feeding. A representative $1 \mathrm{~L}$ sample of rumen contents (solid and liquid) was obtained from four different locations in the rumen (cranial, caudal, right and left sides of the rumen). The rumen content sample was filtered through 2 layers of polyester monofilament fabric (355 $\mu \mathrm{m}$ mesh opening) to separate the liquid and solid fractions. A $5 \mathrm{~mL}$ of rumen fluid was obtained and preserved with methylgreen-formalin-saline solution, inverted ten times, and stored in the dark at room temperature $\left(23 \pm 2^{\circ} \mathrm{C}\right)$ until protozoa were identified and counted as described previously [46]. Samples 
of filtered rumen fluid and samples of rumen digesta were snap frozen in liquid nitrogen and stored at $-80^{\circ} \mathrm{C}$ until DNA extraction.

\section{DNA Extraction and 16s rRNA Gene Amplification}

Frozen rumen samples were freeze dried and ground using a coffee grinder. Microbial DNA was extracted from $\sim 0.1 \mathrm{~g}$ of the freeze dried, ground material using the Zymobiomics DNA extraction kit as per the manufacturer's instructions (Zymo Research, Irvine CA). Concentration and purity of the extracted metagenomic DNA was determined by measuring the ratios of absorbance at 260/280 and 260/230 using a NanoDrop spectrophotometer (Thermo Fisher Scientific, Mississauga, ON, Canada).

Sequencing was performed at Genome Quebec Innovation Center (Montreal, Canada) using the Illumina MiSeq Reagent Kit v2 (500 cycle) following the manufacturer's guidelines. The primers 515F ( $5^{\prime}$ GTGCCAGCMGCCGCGGTAA- 3') and 806R (5' -GGACTACHVGGGTWTCTAAT- 3') targeting the V4 region of the 16s rRNA gene were used to examine both bacterial and archaeal diversity [47]. A 33 cycle PCR using $1 \mu \mathrm{L}$ of a 1 in 10 dilution of genomic DNA and the Fast Start High Fidelity PCR System (Roche, Montreal, $\mathrm{PQ}$ ) was conducted with the following conditions: $94^{\circ} \mathrm{C}$ for $2 \mathrm{~min}$, followed by 33 cycles of $94^{\circ} \mathrm{C}$ for $30 \mathrm{~s}$, $58^{\circ} \mathrm{C}$ for $30 \mathrm{~s}$, and $72^{\circ} \mathrm{C}$ for $30 \mathrm{~s}$, with a final elongation step at $72^{\circ} \mathrm{C}$ for $7 \mathrm{~min}$. Fluidigm Corporation (San Francisco, CA) barcodes were incorporated in a second PCR reaction using the FastStart High Fidelity PCR System under the following conditions: $95^{\circ} \mathrm{C}$ for $10 \mathrm{~min}$, followed by 15 cycles of $95^{\circ} \mathrm{C} \mathrm{for} 15 \mathrm{~s}, 60^{\circ} \mathrm{C}$ for $30 \mathrm{~s}$, and $72^{\circ} \mathrm{C}$ for $1 \mathrm{~min}$, followed by a final elongation step at $72^{\circ} \mathrm{C}$ for $3 \mathrm{~min}$. After amplification, PCR products were assessed in a $2 \%$ agarose gel to confirm adequate amplification. All samples were quantified using the Quant-iT PicoGreen dsDNA Assay Kit (Life Technologies, Carlsbad, CA) and were pooled in equal proportions. Pooled samples were then purified using calibrated Ampure XP beads (Beckman Coulter, Mississauga, ON). The pooled samples (library) were quantified using the Quant-iT PicoGreen dsDNA Assay Kit (Life Technologies, Carlsbad, CA) and the Kapa Illumina GA with Revised Primers-SYBR Fast Universal kit (Kapa Biosystems, Wilmington, MA). Average fragment size was determined using a LabChip GX (PerkinElmer, Waltham, MA, USA) instrument.

Raw fastq files were imported into Qiime2 for sequence analysis [48]. Primer and adapter sequences were removed from sequence files with the plugin 'cutadapt' [49]. Following removal of primer and adapter sequences, the program DADA2 [50] was used for quality control, filtering of any phiX reads present in the sequencing data, and removal of chimeric sequences. Amplicon Sequence variants (ASVs) at strain level resolution (>99.9\% id) were generated using DADA2 [50]. The Mafft program [51] was used to perform a multiple sequence alignment and to mask highly variable regions. A phylogenetic tree was generated with FastTree [52] and taxonomy was assigned to sequences using a Naïve-Bayes classifier trained with the Silva 128 reference database and the 'feature-classifier' plugin [53]. Sequences were subsampled to the lowest number of sequences found in all of the samples to ensure that $\alpha$ - and $\beta$-diversity analysis used the same number of sequences per sample. The plugin, 'core-diversity-metrics' was used to assess microbial diversity within ( $a$-diversity) and between samples ( $\beta$-diversity). The $a$-diversity indices: number of ASVs, and Faith's Phylogenetic Diversity were evaluated for treatment effects. $\beta$-Diversity analysis was 
carried out using weighted and unweighted UniFrac [54]. Environmental variables that had a significant impact on microbiome composition were identified in $\mathrm{R}$ using the envplot function. Sequences were deposited to the Small Reads Archive (NCBI) with accession number PRJNA680383.

\section{Enteric gas emissions and dissolved hydrogen}

Enteric gas production $\left(\mathrm{CH}_{4}\right.$ and $\left.\mathrm{H}_{2}\right)$ was measured in open-circuit calorimetry chambers from day 18 to 21 of every period according to the methods of Beauchemin and McGinn (2006) and McGinn et al. (2004) $[24,36]$. All chambers were calibrated before and after the study by sequentially releasing $0,0.2$, and 0.4 $\mathrm{L} / \mathrm{min}$ of $\mathrm{CH}_{4}$ into each chamber using a mass-flow meter (Omega Engineering, Stamford, CT). Slopes of the best fit calibration regressions were generated to correct emissions for each gas as detailed by McGinn et al. (2004) [55]. Variability in slopes across chambers was less than $5 \%$ and recovery rates ranged from $97-107 \%$. Details of the chamber design and the calculation of $\mathrm{CH}_{4}$ emissions were reported by McGinn et al. (2004) [36]. Hydrogen $\left(\mathrm{H}_{2}\right)$ production was measured at 30-min intervals every 3 $\mathrm{h}$ by collecting air samples from intake air ducts of each chamber. Hydrogen concentration was determined via a $\mathrm{H}_{2}$ breath tester (BreathTracker Digital Microlyzer, QuinTron Instrument Company, Inc., Milwaukee, $\mathrm{WI}, \mathrm{USA})$. Dissolved hydrogen $\left(\mathrm{dH}_{2}\right)$ was measured in ruminal fluid samples collected on $\mathrm{d} 28$ via the fistula at $0,3,6,9$ and 12 hours after feeding. The $\mathrm{dH}_{2}$ concentration was measured using procedures described by Wang et al. (2014) [56]. Briefly, each ruminal fluid sample (35 mL) was quickly transferred into a $50-\mathrm{mL}$ plastic syringe connected to a $20-\mathrm{mL}$ syringe prefilled with $10 \mathrm{~mL} \mathrm{~N}_{2}$ gas. The $\mathrm{N}_{2}$ gas was then injected into the $50-\mathrm{mL}$ syringe, and the syringe was vigorously shaken for 5 min to extract the gases dissolved in the ruminal fluid into the $\mathrm{N}_{2}$ gas phase. The extracted $\mathrm{H}_{2}$ concentration was determined by gas chromatography (Agilent 7890A, Agilent Inc., Palo Alto, CA, USA). The $\mathrm{dH}_{2}$ concentrations in the original ruminal fluid was calculated according to the equation given by Wang et al. (2016) [57].

\section{Calculations and Statistical Analysis}

The daily $\mathrm{CH}_{4}$ flux was determined for each animal and expressed relative to DMI on the day of measurement. Alpha diversity, relative abundance, protozoal counts, rumen fermentation and gas data were analyzed by SAS (SAS Institute, Inc., 2015) using a mixed model procedure that included fixed effects of treatment (3-NOP, OIL and their interaction), random effects of animal, period and group. The treatment effect was examined as a $2 \times 2$ factorial arrangement to determine the main effect of 3-NOP (control and OIL vs. 3-NOP and 3-NOP + OIL), OIL (control and 3-NOP vs OIL and 3-NOP + OIL) and their interaction.

A PERMANOVA based statistical test was used to examine the influence of treatment, rumen phase (liquid vs. solid), or time of sampling on the composition of the microbial community. A Kruskal-Wallis test was used to examine the significance of treatment on Archaea. Independent pairwise comparisons with a Nemenyi test and a Chi-squared approximation was used to identify significant differences 
between treatments. $P$ values were corrected for false discovery rates (FDR). Statistical significance was declared at $P \leq 0.05$ and tendencies were declared at $0.05<P \leq 0.10$.

\section{Declarations}

Acknowledgements: Sequencing was conducted by the staff with the McGill University and Génome Québec Innovation Centre. We thank B. Farr and K. Andrews for their technical assistance and the staff of the Beef Cattle Metabolism Facility for animal care and handling.

Ethics approval and consent to participate: This study was reviewed and approved by the Animal Care Committee at the Lethbridge Research and Development Centre (Protocol\#: KB1607).

Consent for publication: Not applicable

Availability of data and material: Sequence data has been submitted to the Sequence Read Archive with accession numbers PRJNA680383.

Competing interests: The authors declare no conflict of interest. M. Kindermann is an employee of DSM Nutritional Products.

Funding: funding was provided by Agriculture and Agri-Food Canada. DSM Nutritional Products supplied the 3-Nitrooxypropanol. XMZ was supported by National Natural Science Foundation of China grants (31922080 and 32002204).

Authors' Contributions: RJG conceived of research, performed bioinformatics analysis, analyzed and interpreted data and wrote manuscript. XMZ processed samples, conducted statistical analysis of data and contributed to manuscript preparation, MLS collected samples during animal trial, DV collected samples during animal trial, LKJ involved in design of Animal trial and provided advice on analysis of data SMG contributed to measurement of enteric gas emission, MK contributed to data analysis and manuscript preparation, MW contributed resources, ZLT provided guidance \& involved in interpretation of results, KAB conceived of research, designed animal trial, contributed resources, was involved with interpretation of results and writing of manuscript.

\section{References}

1. Smith P, Bustamante $\mathrm{M}$, Ahammad H, Clark H, Dong H: Agriculture, forestry and other land use (AFOLU). In Climate Change 2014: Mitigation of Climate Change Contribution of Working Group III to the Fifth Assessment Report of the Intergovernmental Panel on Climate Change (Edenhofer O, PichsMadruga R, Sokona Y, Minx JC, Farahani E, Kadner S, Seyboth K, Adler A, Baum I, Brunner S, et al eds.). United Kingdom and New York, NY, USA.; 2014.

2. Johnson KA, Johnson DE. Methane emissions from cattle. J Anim Sci. 1995;73:2483-92. 
3. Martin C, Morgavi DP, Doreau M. Methane mitigation in ruminants: from microbe to the farm scale. Animal. 2010;4:351-65.

4. Beauchemin KA, Ungerfeld EM, Eckard RJ, Wang M. Review. Fifty years of research on rumen methanogenesis: lessons learned and future challenges for mitigation. Animal. 2020;14:s2-16.

5. Lopes JC, de Matos LF, Harper MT, Giallongo F, Oh J, Gruen D, Ono S, Kindermann M, Duval S, Hristov AN. Effect of 3-nitrooxypropanol on methane and hydrogen emissions, methane isotopic signature, and ruminal fermentation in dairy cows. J Dairy Sci. 2016;99:5335-44.

6. Martinez-Fernandez G, Abecia L, Arco A, Cantalapiedra-Hijar G, Martin-Garcia Al, Molina-Alcaide E, Kindermann M, Duval S, Yanez-Ruiz DR. Effects of ethyl-3-nitrooxy propionate and 3-

nitrooxypropanol on ruminal fermentation, microbial abundance, and methane emissions in sheep. $J$ Dairy Sci. 2014;97:3790-9.

7. Vyas D, McGinn SM, Duval SM, Kindermann MK, Beauchemin KA. Optimal dose of 3nitrooxypropanol for decreasing enteric methane emissions from beef cattle fed high-forage and high-grain diets. Anim Prod Sci. 2016;58:1049-55.

8. McGinn SM, Flesch TK, Beauchemin KA, Shreck A, Kindermann M. Micrometeorological Methods for Measuring Methane Emission Reduction at Beef Cattle Feedlots: Evaluation of 3-nitrooxypropanol Feed Additive. J Environ Qual. 2019;48:1454-61.

9. Hristov AN, Oh J, Giallongo F, Frederick TW, Harper MT, Weeks HL, Branco AF, Moate PJ, Deighton MH, Williams SR, et al. An inhibitor persistently decreased enteric methane emission from dairy cows with no negative effect on milk production. Proc Natl Acad Sci U S A. 2015;112:10663-8.

10. Melgar A, Welter KC, Nedelkov K, Martins C, Harper MT, Oh J, Raisanen SE, Chen X, Cueva SF, Duval S, Hristov AN. Dose-response effect of 3-nitrooxypropanol on enteric methane emissions in dairy cows. J Dairy Sci. 2020;103:6145-56.

11. Vyas D, Alemu AW, McGinn SM, Duval SM, Kindermann M, Beauchemin KA. The combined effects of supplementing monensin and 3-nitrooxypropanol on methane emissions, growth rate, and feed conversion efficiency in beef cattle fed high-forage and high-grain diets. J Anim Sci. 2018;96:292338.

12. Guyader J, Ungerfeld EM, Beauchemin KA. Redirection of Metabolic Hydrogen by Inhibiting Methanogenesis in the Rumen Simulation Technique (RUSITEC). Front Microbiol. 2017;8:393.

13. Zhang XM, Gruninger RJ, Alemu AW, Wang M, Tan ZL, Kindermann M, Beauchemin KA. 3Nitrooxypropanol supplementation had little effect on fiber degradation and microbial colonization of forage particles when evaluated using the in situ ruminal incubation technique. J Dairy Sci. 2020;103:8986-97.

14. Duin EC, Wagner T, Shima S, Prakash D, Cronin B, Yáñez-Ruiz DR, Duval S, Rümbeli R, Stemmler RT, Thauer RK, Kindermann M. Mode of action uncovered for the specific reduction of methane emissions from ruminants by the small molecule 3-nitrooxypropanol. Proc Natl Acad Sci U S A. 2016;113::E3185. 
15. Haisan J, Sun y, Guan LL, Beauchemin KA, Iwaasa A, Duval S, Kindermann M, Barreda DR, Oba M. The effects of feeding 3-nitrooxypropanol at two doses on milk production, rumen fermentation, plasma metabolites, nutrient digestibility, and methane emissions in lactating Holstein cows. Anim Prod Sci. 2016;57:282-9.

16. Martinez-Fernandez G, Duval S, Kindermann M, Schirra HJ, Denman SE, McSweeney CS. 3-NOP vs. Halogenated Compound: Methane Production, Ruminal Fermentation and Microbial Community Response in Forage Fed Cattle. Front Microbiol. 2018;9:1582.

17. Romero-Perez A, Okine EK, McGinn SM, Guan LL, Oba M, Duval SM, Kindermann M, Beauchemin KA. The potential of 3-nitrooxypropanol to lower enteric methane emissions from beef cattle. J Anim Sci. 2014;92:4682-93.

18. Beauchemin KA. Dietary mitigation of enteric methane from cattle. CAB Reviews: Perspectives in Agriculture, Veterinary Science, Nutrition and Natural Resources 2009;4.

19. Adeyemi KD, Sazili AQ, Ebrahimi M, Samsudin AA, Alimon AR, Karim R, Karsani SA, Sabow AB. Effects of blend of canola oil and palm oil on nutrient intake and digestibility, growth performance, rumen fermentation and fatty acids in goats. Anim Sci J. 2016;87:1137-47.

20. Patra AK. The effect of dietary fats on methane emissions, and its other effects on digestibility, rumen fermentation and lactation performance in cattle: A meta-analysis. Livest Sci. 2013;155:24454.

21. Beauchemin KA, McGinn SM, Benchaar C, Holtshausen L. Crushed sunflower, flax, or canola seeds in lactating dairy cow diets: effects on methane production, rumen fermentation, and milk production. $J$ Dairy Sci. 2009;92:2118-27.

22. Pinares-Patiño CS, Franco FE, Molano G, Kjestrup H, Sandoval E, MacLean S, Battistotti M, Koolaard $\mathrm{J}$, Laubach J. Feed intake and methane emissions from cattle grazing pasture sprayed with canola oil. Livest Sci. 2016;184:7-12.

23. Beauchemin KA, McGinn SM. Methane emissions from beef cattle: Effects of fumaric acid, essential oil, and canola oil. J Anim Sci. 2006;84:1489.

24. Beauchemin KA, Kreuzer M, O'Mara F, McAllister TA. Nutritional management for enteric methane abatement: a review. Aust J Exp Agric. 2008;48:21-7.

25. Ramos AFO, Terry SA, Holman DB, Breves G, Pereira LGR, Silva AGM, Chaves AV. Tucuma Oil Shifted Ruminal Fermentation, Reducing Methane Production and Altering the Microbiome but Decreased Substrate Digestibility Within a RUSITEC Fed a Mixed Hay - Concentrate Diet. Front Microbiol. 2018;9:1647.

26. Yanza YR, Szumacher-Strabel M, Jayanegara A, Kasenta AM, Gao M, Huang H, Patra AK, Warzych E, Cieslak $A$. The effects of dietary medium-chain fatty acids on ruminal methanogenesis and fermentation in vitro and in vivo: A meta-analysis. J Anim Physiol Anim Nutr (Berl). 2020. doi:10.1111/jpn.13367.

27. Zhang XM, Smith ML, Gruninger RJ, Kung L Jr, Vyas D, McGinn SM, Kindermann M, Wang M, Tan ZL, Beauchemin KA. Combined effects of 3-nitrooxypropanol and canola oil supplementation on 
methane emissions, rumen fermentation and biohydrogenation, and total-tract digestibility in beef cattle. J Anim Sci 2021:doi: 10.1093/jas/skab1081.

28. Vyas D, McGinn SM, Duval SM, Kindermann M, Beauchemin KA. Effects of sustained reduction of enteric methane emissions with dietary supplementation of 3-nitrooxypropanol on growth performance of growing and finishing beef cattle. J Anim Sci. 2016;94:2024-34.

29. Stewart C, Flint H, Bryant M. The rumen bacteria. London: Blackie; 1997.

30. Ungerfeld EM. Metabolic Hydrogen Flows in Rumen Fermentation: Principles and Possibilities of Interventions. Front Microbiol. 2020;11:589.

31. McAllister TA, Newbold CJ. Redirecting rumen fermentation to reduce methanogenesis. Aust $J$ Exp Agric 2008;48.

32. Janssen $\mathrm{PH}$. Influence of hydrogen on rumen methane formation and fermentation balances through microbial growth kinetics and fermentation thermodynamics. Anim Feed Sci Technol. 2010;160:122.

33. Romero-Perez A, Okine EK, McGinn SM, Guan LL, Oba M, Duval SM, Kindermann M, Beauchemin KA. Sustained reduction in methane production from long-term addition of 3-nitrooxypropanol to a beef cattle diet. J Anim Sci. 2015;93:1780-91.

34. Guyader J, Eugène M, Meunier B, Doreau M, Morgavi DP, Silberberg M, Rochette $Y$, Gerard C, Loncke $C$, Martin C. Additive methane-mitigating effect between linseed oil and nitrate fed to cattle. J Anim Sci. 2015;93:3564-77.

35. Henderson G, Yilmaz P, Kumar S, Forster RJ, Kelly WJ, Leahy SC, Guan LL, Janssen PH. Improved taxonomic assignment of rumen bacterial 16S rRNA sequences using a revised SILVA taxonomic framework. PeerJ. 2019;7:e6496.

36. Solden LM, Hoyt DW, Collins WB, Plank JE, Daly RA, Hildebrand E, Beavers TJ, Wolfe R, Nicora CD, Purvine SO, et al. New roles in hemicellulosic sugar fermentation for the uncultivated Bacteroidetes family BS11. ISME J. 2017;11:691-703.

37. Xue D, Chen H, Chen F, He Y, Zhao C, Zhu D, Zeng L, Li W. Analysis of the rumen bacteria and methanogenic archaea of yak (Bos grunniens) steers grazing on the Qinghai-Tibetan Plateau. J Livestock Science. 2016;188:61-71.

38. Popova M, McGovern E, McCabe MS, Martin C, Doreau M, Arbre M, Meale SJ, Morgavi DP, Waters SM. The Structural and Functional Capacity of Ruminal and Cecal Microbiota in Growing Cattle Was Unaffected by Dietary Supplementation of Linseed Oil and Nitrate. Front Microbiol. 2017;8:937.

39. Scharen M, Frahm J, Kersten S, Meyer U, Hummel J, Breves G, Danicke S. Interrelations between the rumen microbiota and production, behavioral, rumen fermentation, metabolic, and immunological attributes of dairy cows. J Dairy Sci. 2018;101:4615-37.

40. Benchaar C, Hassanat F, Martineau R, Gervais R. Linseed oil supplementation to dairy cows fed diets based on red clover silage or corn silage: Effects on methane production, rumen fermentation, nutrient digestibility, N balance, and milk production. J Dairy Sci. 2015;98:7993-8008. 
41. Yang HE, Zotti CA, McKinnon JJ, McAllister TA. Lactobacilli Are Prominent Members of the Microbiota Involved in the Ruminal Digestion of Barley and Corn. Front Microbiol. 2018;9::718.

42. Hamlin LJ, Hungate RE. Culture and physiology of a starch-digesting bacterium (Bacteroides amylophilus n. sp.) from the bovine rumen. J Bacteriol. 1956;72:548-54.

43. van Gylswyk NO. Succiniclasticum ruminis gen. nov., sp. nov., a ruminal bacterium converting succinate to propionate as the sole energy-yielding mechanism. Int J Syst Bacteriol. 1995;45:297300 .

44. Pope PB, Smith W, Denman SE, Tringe SG, Barry K, Hugenholtz P, McSweeney CS, McHardy AC, Morrison M. Isolation of Succinivibrionaceae implicated in low methane emissions from Tammar wallabies. Science. 2011;333:646-8.

45. Ramayo-Caldas Y, Zingaretti L, Popova M, Estelle J, Bernard A, Pons N, Bellot P, Mach N, Rau A, Roume $\mathrm{H}$, et al. Identification of rumen microbial biomarkers linked to methane emission in Holstein dairy cows. J Anim Breed Genet. 2020;137:49-59.

46. Ogimoto K, Imai S: Atlas of Rumen Microbiology. In. Tokyo, Japan.: Japan Sci. Soc. Press; 1981: 158.

47. Caporaso JG, Lauber CL, Walters WA, Berg-Lyons D, Huntley J, Fierer N, Owens SM, Betley J, Fraser L, Bauer $\mathrm{M}$, et al. Ultra-high-throughput microbial community analysis on the Illumina HiSeq and MiSeq platforms. ISME J. 2012;6:1621-4.

48. Bolyen E, Rideout JR, Dillon MR, Bokulich NA, Abnet CC, Al-Ghalith GA, Alexander H, Alm EJ, Arumugam M, Asnicar F, et al. Reproducible, interactive, scalable and extensible microbiome data science using QIIME 2. Nat Biotechnol. 2019;37:852-7.

49. Martin M. Cutadapt removes adapter sequences from high-throughput sequencing reads. EMBnetjournal. 2011;17:10-2.

50. Callahan BJ, McMurdie PJ, Rosen MJ, Han AW, Johnson AJ, Holmes SP. DADA2: High-resolution sample inference from Illumina amplicon data. Nat Methods. 2016;13:581-3.

51. Katoh K, Standley DM. MAFFT multiple sequence alignment software version 7: improvements in performance and usability. Mol Biol Evol. 2013;30:772-80.

52. Price MN, Dehal PS, Arkin AP. FastTree 2-approximately maximum-likelihood trees for large alignments. PLoS One. 2010;5:e9490.

53. Bokulich NA, Kaehler BD, Rideout JR, Dillon M, Bolyen E, Knight R, Huttley GA, Caporaso GJ. Optimizing taxonomic classification of marker-gene amplicon sequences with QIIME 2's q2-featureclassifier plugin. Microbiome. 2018;6:90.

54. Lozupone C, Lladser ME, Knights D, Stombaugh J, Knight R. UniFrac: an effective distance metric for microbial community comparison. ISME J. 2011;5:169-72.

55. McGinn SM, Beauchemin KA, Coates T, Colombatto D. Methane emissions from beef cattle: Effects of monensin, sunflower oil, enzymes, yeast, and fumaric acid. J Anim Sci. 2004;82::3346. 
56. Wang M, Sun XZ, Janssen PH, Tang SX, Tan ZL. Responses of methane production and fermentation pathways to the increased dissolved hydrogen concentration generated by eight substrates in in vitro ruminal cultures. Anim Feed Sci Technol. 2014;194:1-11.

57. Wang M, Wang R, Janssen PH, Zhang XM, Sun XZ, Pacheco D, Tan ZL. Sampling procedure for the measurement of dissolved hydrogen and volatile fatty acids in the rumen of dairy cows. J Anim Sci. 2016;94:1159-69.

\section{Figures}
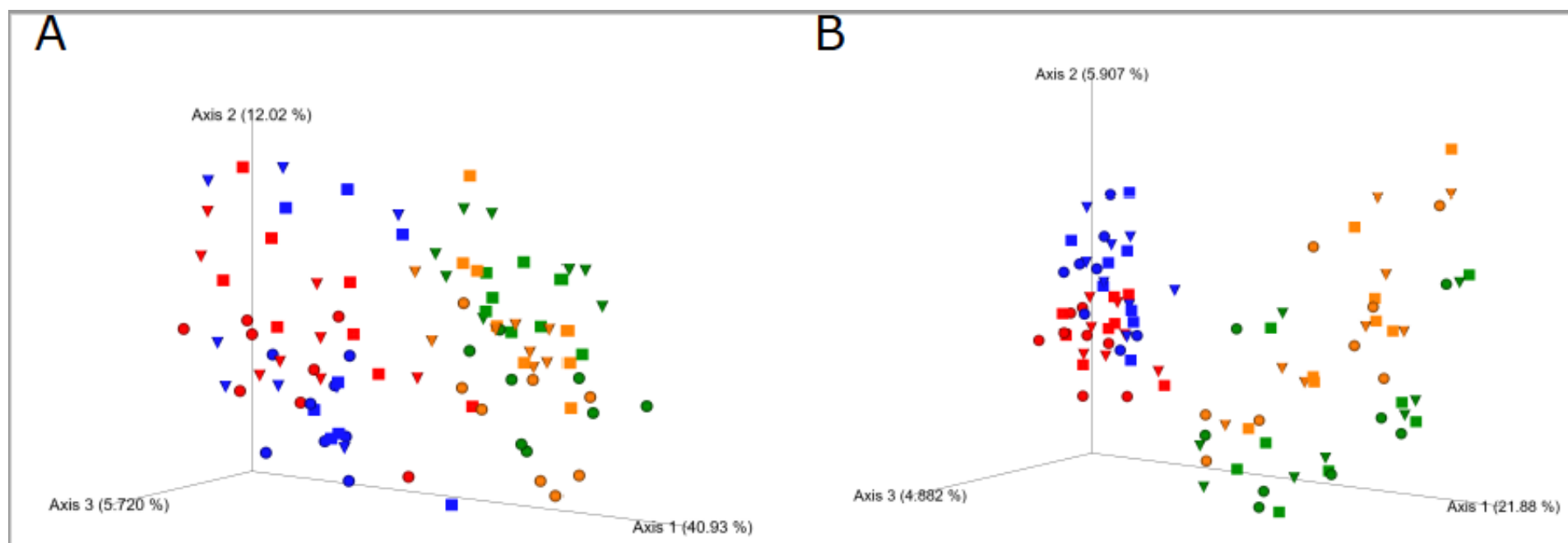

C

$\mathrm{D}$
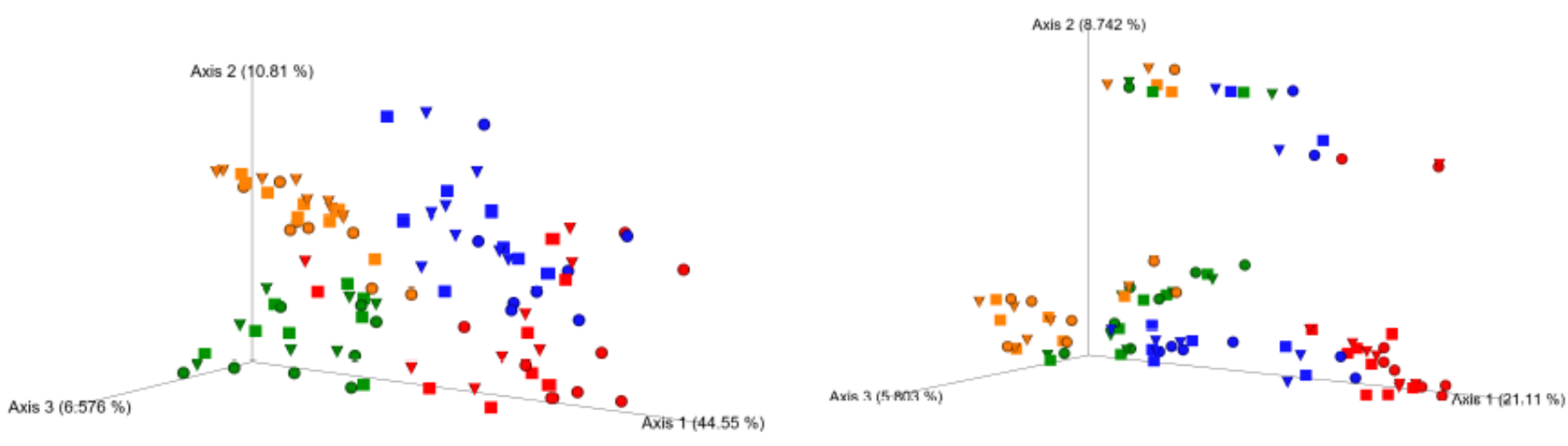

Figure 1

Impact of methane inhibitors on the bacterial and archaeal community in rumen digesta and rumen fluid from cattle fed a control diet (CON, red), a control diet supplemented with canola oil (OIL, green), 3-NOP (3-NOP, blue), or a combination of 3-NOP and oil (3-NOP+OIL, orange). Principle components plots are based on UniFrac distances and colored to show the impacts of time and treatment on microbiome composition. A) weighted UniFrac plot of rumen fluid samples, B) unweighted UniFrac Plot of rumen fluid, C) weighted UniFrac plot of rumen digesta, D) unweighted UniFrac plot of rumen digesta. Samples taken 
prior to feeding are shown as circles, samples taken $6 \mathrm{~h}$ after feeding are shown as squares, samples taken $12 \mathrm{~h}$ after feeding are shown as triangles.
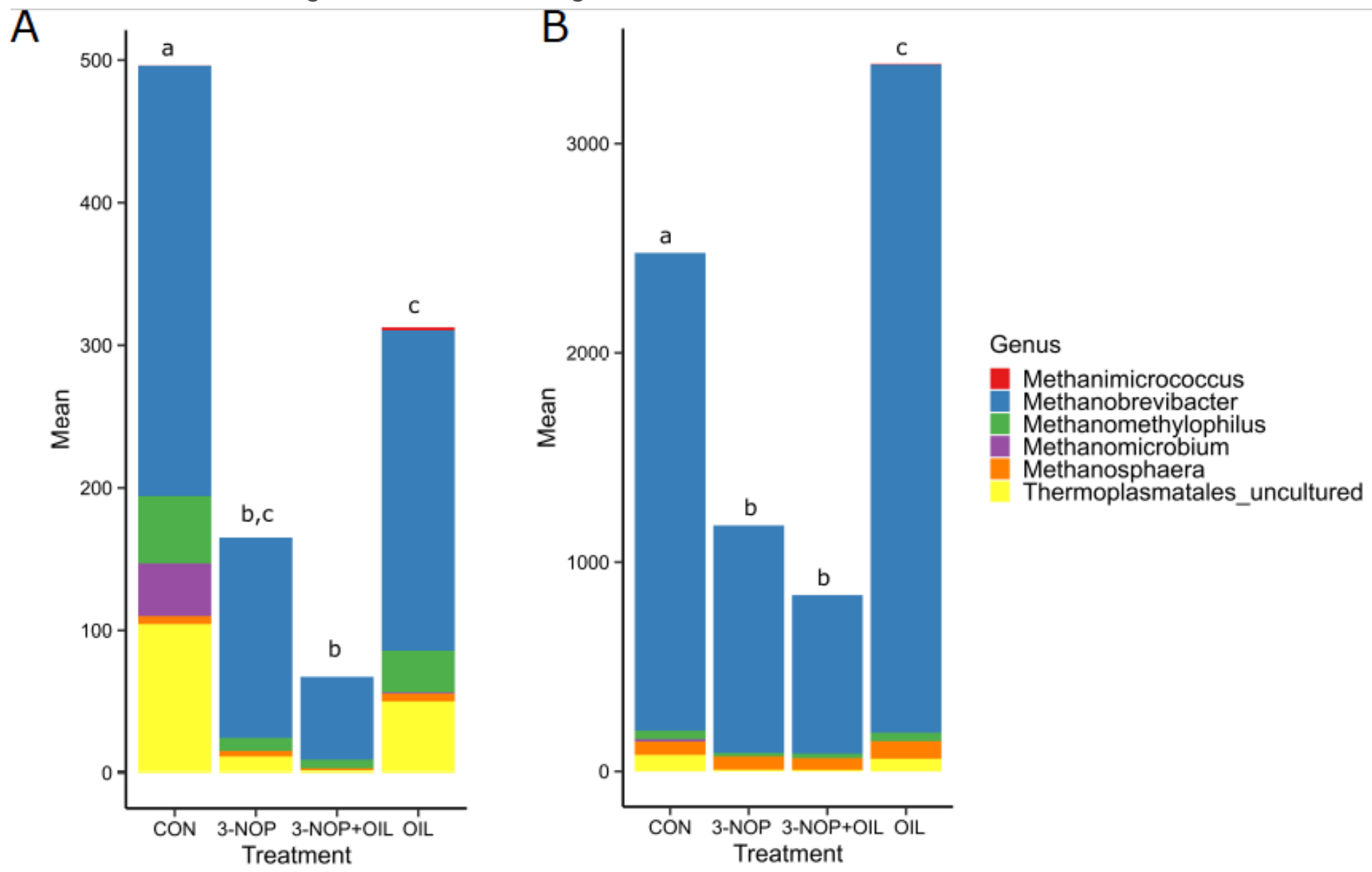

\section{Figure 2}

Impact of $\mathrm{CH} 4$ inhibitors on the abundance of rumen methanogens in A) Rumen Fluid and B) Rumen digesta. The mean count of ASVs assigned to genera in the phylum Euryarchaeota is shown. Treatments resulting in statistically significant differences in the total count of ASVs classified within the phylum Euryarchaeota are indicted by a unique letter in each panel. 

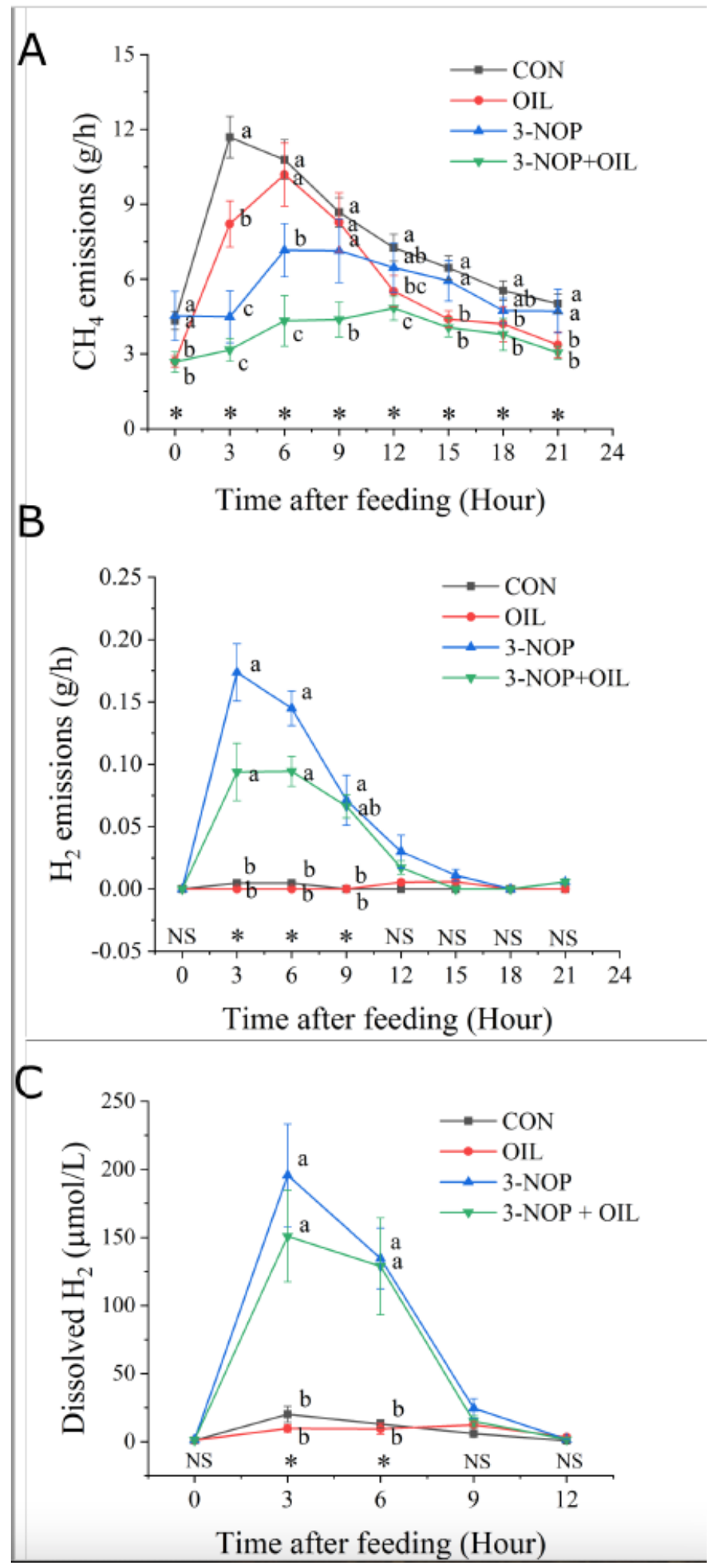

\section{Figure 3}

Enteric $\mathrm{CH} 4$ (A) and H2 (B) emissions, and dissolved $\mathrm{H} 2$ in rumen fluid for animals fed the CON, OIL, 3NOP and 3-NOP+OIL dietary treatments over $24 \mathrm{~h}$ after feeding. Dissolved $\mathrm{H} 2$ levels were only measured over the first 12 hours after feeding. Error bars indicate the SD. Asterisks $\left(^{*}\right)$ and different lowercase letters indicate time points in which the main effect of treatment is significant $(P<0.05)$, NS indicates no 
significant difference. $\mathrm{CON}=$ control, OIL = canola oil, 3-NOP = 3-nitrooxypropanol, 3-NOP+OIL = 3nitrooxypropanol and canola oil.
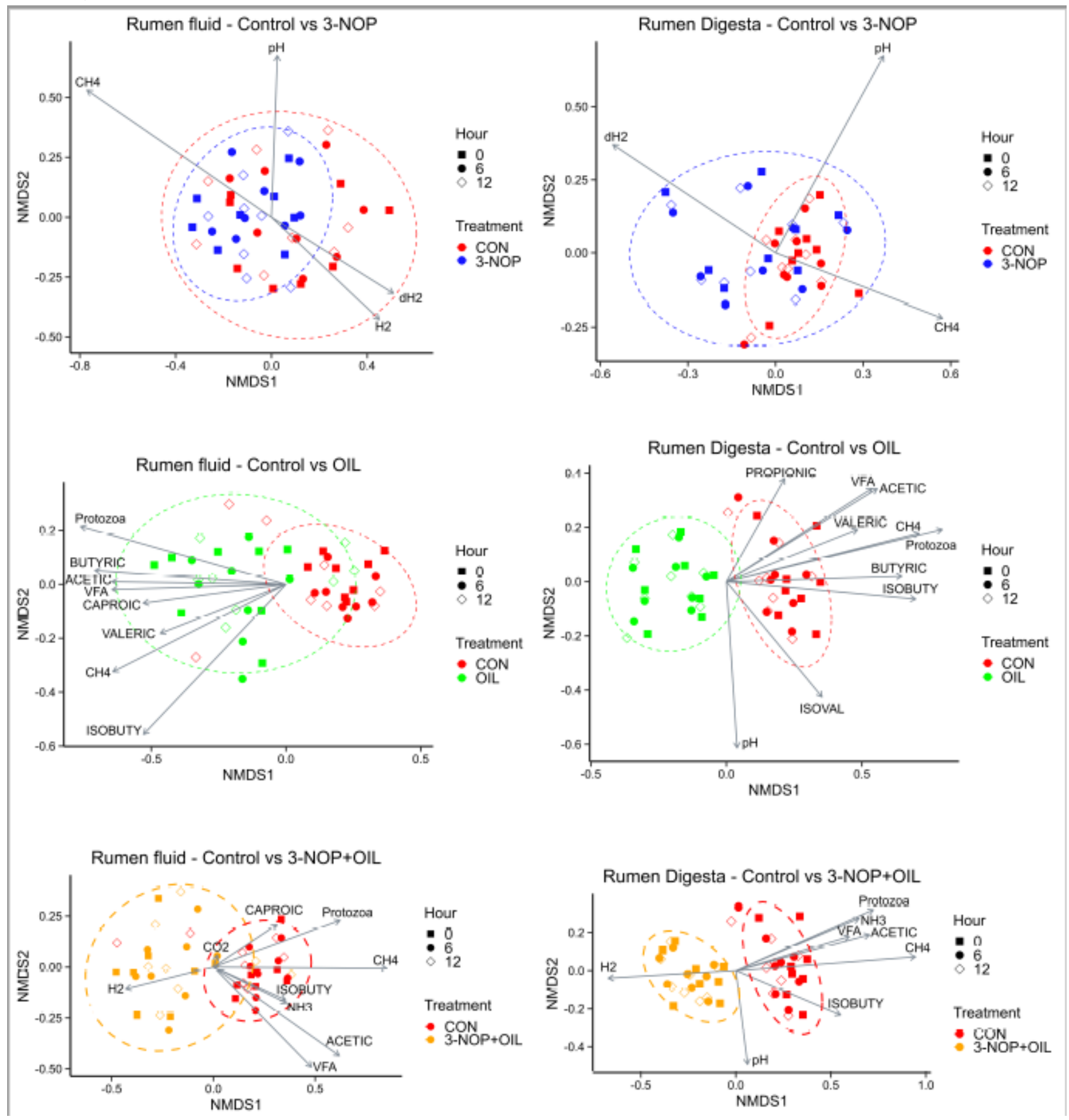

Figure 4

Impact of 3-NOP, OIL, and 3-NOP+OIL on the bacterial and archaeal community in rumen digesta and rumen fluid. Non-metric multidimensional scaling (NMDS) of the Bray-Curtis dissimilarity is shown to compare the samples as a function treatment and time. Vectors having a statistically significant association $(P<0.05)$ with the ordinations are included. Vector length is proportional to the degree of correlation between the environmental parameter and the ordination. Vector abbreviations: $\mathrm{H} 2 \mathrm{CO} 2, \mathrm{CH} 4$ 
emissions adjusted for dry matter intake. dH2: dissolved hydrogen, ISOBUTY: isobutyric acid, ISOVAL: isovaleric acid, VFA: total VFA concentration.

\section{Supplementary Files}

This is a list of supplementary files associated with this preprint. Click to download.

- SupplementaryTables.docx 